\title{
Co-targeting of Tiam1/Rac1 and Notch ameliorates chemoresistance against doxorubicin in a biomimetic 3D lymphoma model
}

\author{
Muhammad Ikram ${ }^{1}$, Yeseon Lim ${ }^{1}$, Sun-Yong Baek ${ }^{1}$, Songwan Jinn ${ }^{2}$, Young Hun \\ Jeong ${ }^{3}$, Jong-Young Kwak ${ }^{4}$ and Sik Yoon ${ }^{1}$ \\ ${ }^{1}$ Department of Anatomy, Pusan National University School of Medicine, Yangsan 50612, Korea \\ ${ }^{2}$ Department of Mechanical Engineering, Korea Polytechnic University, Siheung 15073, Korea \\ ${ }^{3}$ Department of Mechanical Engineering, Kyungpook National University, Daegu 41566, Korea \\ ${ }^{4}$ Department of Pharmacology, Ajou University School of Medicine, Suwon 16499, Korea
}

Correspondence to: Sik Yoon, email: sikyoon@pusan.ac.kr

Keywords: tiam1; notch; chemoresistance; doxorubicin; 3D lymphoma model

Received: August 31, $2017 \quad$ Accepted: November 16, $2017 \quad$ Published: December 08, 2017

Copyright: Ikram et al. This is an open-access article distributed under the terms of the Creative Commons Attribution License 3.0 (CC BY 3.0), which permits unrestricted use, distribution, and reproduction in any medium, provided the original author and source are credited.

\section{ABSTRACT}

Lymphoma is a heterogeneous disease with a highly variable clinical course and prognosis. Improving the prognosis for patients with relapsed and treatmentresistant lymphoma remains challenging. Current in vitro drug testing models based on 2D cell culture lack natural tissue-like structural organization and result in disappointing clinical outcomes. The development of efficient drug testing models using 3D cell culture that more accurately reflects in vivo behaviors is vital. Our aim was to establish an in vitro 3D lymphoma model that can imitate the in vivo 3D lymphoma microenvironment. Using this model, we explored strategies to enhance chemosensitivity to doxorubicin, an important chemotherapeutic drug widely used for the treatment of hematological malignancies. Lymphoma cells grown in this model exhibited excellent biomimetic properties compared to conventional 2D culture including (1) enhanced chemotherapy resistance, (2) suppressed rate of apoptosis, (3) upregulated expression of drug resistance genes (MDR1, MRP1, BCRP and HIF1a), (4) elevated levels of tumor aggressiveness factors including Notch (Notch-1, $-2,-3$, and -4) and its downstream molecules (Hes-1 and Hey-1), VEGF and MMPs (MMP-2 and MMP-9), and (5) enrichment of a lymphoma stem cell population. Tiam1, a potential biomarker of tumor progression, metastasis, and chemoresistance, was activated in our 3D lymphoma model. Remarkably, we identified two synergistic therapeutic oncotargets, Tiam1 and Notch, as a strategy to combat resistance against doxorubicin in EL4 T and A20 B lymphoma. Therefore, our data suggest that our 3D lymphoma model is a promising in vitro research platform for studying lymphoma biology and therapeutic approaches.

\section{INTRODUCTION}

Lymphoma is the most common blood cancer. The incidence of malignant lymphoma around the world has been increasing at a rate of 3-4\% over the last four decades. This is most likely due to improved diagnostic techniques, growth and aging of the world population, the recent trends in the acquired immune deficiency syndrome (AIDS) epidemic, and the rising number of cancer-causing behaviors although the reasons behind this lymphoma epidemic are still poorly understood [1]. Despite a better understanding of the biology of lymphoma and many important therapeutic advances in lymphoma treatments in the past decade, improving the prognosis for patients with relapsed and treatment-resistant disease remains an important challenge [2]. In particular, a major hurdle on the road to the discovery and development of new drugs is the lack of adequate testing models. Furthermore, one 
of the most important steps in developing a potential therapeutic drug is target identification.

Conventional 2-dimensional (2D) cell culture models do not accurately reflect the true biologic responses of cells in the human body where cells exist in a 3-dimensional (3D) microenvironment and cell-cell/ cell-extracellular matrix (ECM) interactions occur through biochemical and mechanical cues [3-4]. Therefore, current in vitro drug testing models based on $2 \mathrm{D}$ cell culture systems result in disappointing clinical outcomes, and the invention of more efficient drug testing models using 3D cell culture systems is indispensable for the development of new drugs. Recent advances in cell biology, microfabrication techniques, and tissue engineering have enabled the development of a wide range of $3 \mathrm{D}$ cell culture technologies including multicellular spheroids, organoids, scaffolds, hydrogels, organs-on-chips, and 3D bioprinting, which are potentially useful to restore the morphological, functional, and microenvironmental features of human tissues and organs [5]. We recently reported the fabrication of a novel, physically gelated, bioactive, alginate/marine collagen/agarose (AmCA) composite hydrogel as a valuable matrix for biomimetic 3D cell spheroid formation and proposed its ability to efficiently create $3 \mathrm{D}$ multicellular spheroids for lymphoma cells [6].

Doxorubicin is one of the most important chemotherapeutic drugs, and it is widely used for the treatment of various types of tumors including hematological malignancies [7]. However, resistance to doxorubicin is a major obstacle to its clinical utility resulting in treatment failures, recurrences, and the need for high-dose therapy. Thus, in recent years, a great deal of attention has been paid to the development of strategies to circumvent its resistance mechanisms. It has been found that protein phosphatase $2 \mathrm{~A}(\mathrm{PP} 2 \mathrm{~A})$, which is a key tumor suppressor; cyclosporine $\mathrm{A}$, which is a modifier of multidrug resistance; and anti-multidrug resistance protein 1 (anti-MDR1) hammerhead ribozymes, which are modulators of MDR1-mediated drug resistance, potentiate the anticancer activity of doxorubicin in experimental hepatocellular carcinoma models [8-10]. To date, however, none of the studies has demonstrated benefits in clinical trials.

The Notch signaling pathway, a highly conserved cell signaling system present in most multicellular organisms, plays pivotal roles in regulating many cellular processes such as proliferation, survival, apoptosis, stem cell renewal and maintenance, cell fate specification, and differentiation [11]. Moreover, dysregulated Notch signaling is responsible for the development and progression of a wide range of human malignancies, including both solid tumors and hematologic malignancies [12-14]. Recently, it has been shown that the Notch pathway is also involved in drug resistance to tumor therapy [15]. Thus, in recent years much attention has been focused on Notch as a potential therapeutic target for the treatment of tumors by overcoming drug resistance of tumor cells and tumor recurrence $[13,16]$.

T-cell lymphoma invasion and metastasis 1 (Tiam1), a Rac1-specific guanine nucleotide exchange factor, was first identified as an invasion and metastasis-related gene [17]. Aberrant expression or mutations of Tiam 1 has been shown to be associated with a variety of human cancer types including extranodal NK/T-cell lymphoma and chronic lymphocytic leukemia $[18,19]$. Tiam1/Rac1 signaling is critically involved in tumor cell progression, invasion, and metastasis $[13,20]$. Furthermore, it was shown that multidrug-resistant lymphoma cell lines express a higher Tiam1 level compared to multidrugsensitive lymphoma cell lines [21]. Recently, it has been demonstrated that targeting Tiam1/Rac1 by using Tiam1 siRNA or inhibitors can reduce the chemoresistance in the proliferative and resistant pool of chronic lymphocytic leukemia (CLL) cells, which is considered to be associated with their recurrent relapses [22].

Thus, the aim of this work was to establish an effective in vitro 3D lymphoma model and to develop an efficient strategy to enhance chemosensitivity to doxorubicin using a new bioactive matrix for 3D cell culture, AmCA composite hydrogel. Importantly, we report that the combined inhibition of dual oncotargets, Tiam1 and Notch, could be a new therapeutic approach to overcome the resistance of EL4 T and A20 B lymphoma cells against doxorubicin.

\section{RESULTS}

\section{D microenvironment in AmCA hydrogels promotes resistance against antitumor agents for lymphoma}

As tumor cells grown in 3D models that accurately reflect the 3D nature of the in vivo microenvironment are considered to exhibit a higher level of drug resistance over those in traditional 2D monolayer, we hypothesized that the 3D multicellular lymphoma spheroids grown within AmCA hydrogels may exhibit enhanced chemotherapeutic resistance to antitumor agents for lymphoma compared to cells cultured in 2D. To evaluate effects of the 3D microenvironment provided by AmCA hydrogels on drug resistance against various antitumor agents for lymphoma, we seeded EL4 or A20 cells at $1 \times 10^{5}$ cells/ $\mathrm{ml}$ into these hydrogels. On day 7 , when multicellular spheroids were formed in 3D conditions, the cells grown in $2 \mathrm{D}$ or $3 \mathrm{D}$ cultures were exposed to $1 \mu \mathrm{M}$ doxorubicin, $0.5 \mu \mathrm{M}$ docetaxel, $1 \mu \mathrm{M}$ vincristine, $5 \mu \mathrm{M}, 5$-fluorouracil (5-FU), $100 \mu \mathrm{M}$ resveratrol, and $10 \mu \mathrm{M}$ curcumin for $24 \mathrm{~h}$. A WST-1-based colorimetric cell cytotoxicity assay was employed to evaluate the ability of each antitumor agent to induce cytotoxicity. A cell viability assay showed a significant difference between 2D and 3D cultures 
with regard to antitumor agent sensitivity. In EL4 cells, the rates of resistance in $3 \mathrm{D}$ cultures to doxorubicin, docetaxel, vincristine, 5-FU, resveratrol, and curcumin were $71.4 \pm 4.4 \%$ (versus $54.6 \pm 2.8 \%$ for $2 \mathrm{D}$ ), $77.7 \pm$ $2.7 \%$ (versus $50.9 \pm 4.9 \%$ for $2 \mathrm{D}$ ), $89.4 \pm 7.8$ (versus 48.9 $\pm 1.2 \%$ for $2 \mathrm{D}$ ), $76.1 \pm 6.1 \%$ (versus $59.6 \pm 3.3 \%$ for $2 \mathrm{D}$ ), $93.4 \pm 5.1 \%$ (versus $50.1 \pm 2.0 \%$ for $2 \mathrm{D}$ ), and $78.9 \pm 3.6 \%$ (versus $40.9 \pm 4.8 \%$ for $2 \mathrm{D}$ ), respectively (Figure $1 \mathrm{~A}$ ). An untreated condition (considered as $100 \%$ ) grown during the same time served as the control. A similar effect was also seen with A20 cell spheroids, the rates of resistance in $3 \mathrm{D}$ cultures to doxorubicin, docetaxel, vincristine, 5-FU, resveratrol, and curcumin were $69.0 \pm 1.3 \%$ (versus 40.4 $\pm 1.0 \%$ for $2 \mathrm{D}$ ), $85.4 \pm 7.3 \%$ (versus $51.0 \pm 11 \%$ for $2 \mathrm{D}$ ),
$84.8 \pm 2.2$ (versus $55.8 \pm 2.3 \%$ for $2 \mathrm{D}$ ), $87.3 \pm 1.94 \%$ (versus $49.0 \pm 1.6 \%$ for $2 \mathrm{D}$ ), $77.6 \pm 8.3 \%$ (versus 27.0 $\pm 1 \%$ for $2 \mathrm{D}$ ), and $90.0 \pm 11.4 \%$ (versus $57.9 \pm 8.3 \%$ for 2D), respectively (Figure 1B). These data demonstrate that the antitumor agent resistance of both cell types was robustly augmented in $3 \mathrm{D}$ cultures compared to $2 \mathrm{D}$ cultures.

As tumor cells grown in $3 \mathrm{D}$ models that adequately reflect the $3 \mathrm{D}$ nature of the in vivo microenvironment are thought to be more resistant to apoptosis induced by antitumor agents than those in traditional 2D monolayer cultures, we hypothesized that the multicellular 3D lymphoma spheroids grown within AmCA hydrogels may be less vulnerable to induction of apoptosis by antitumor
A

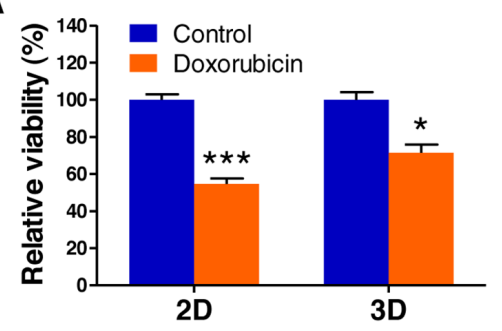

5-FU

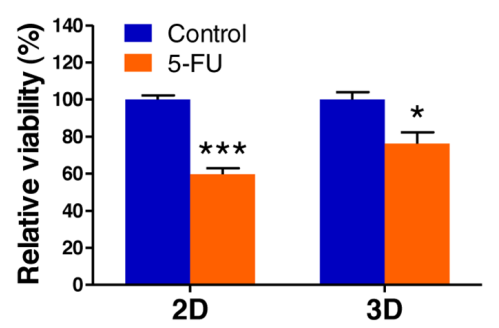

B
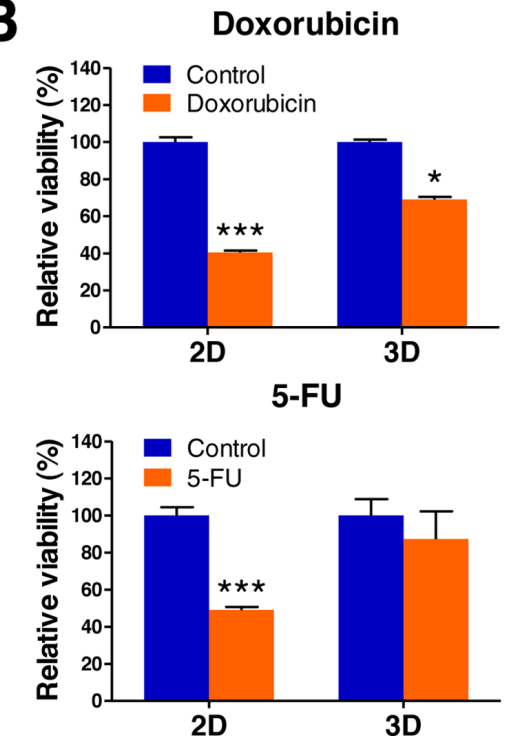

Docetaxel

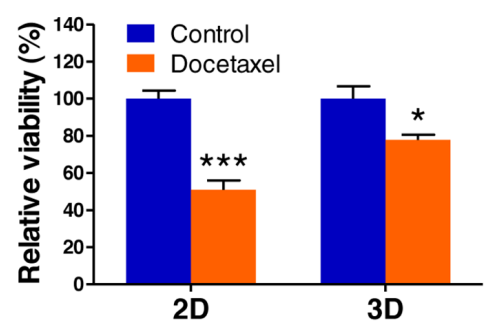

Resveratrol

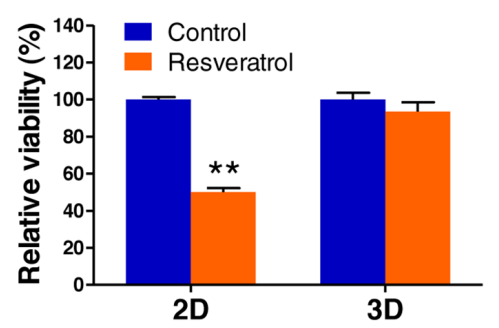

Docetaxel

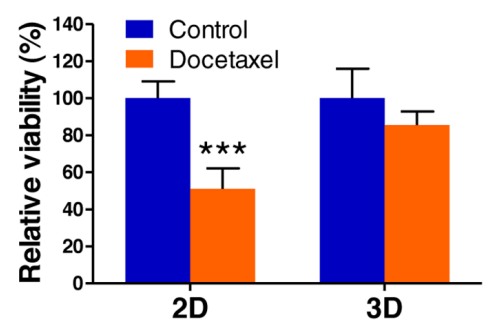

Resveratrol

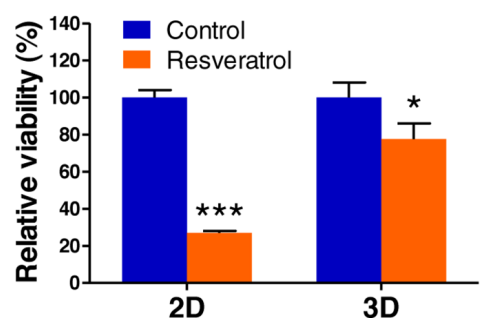

Vincristine

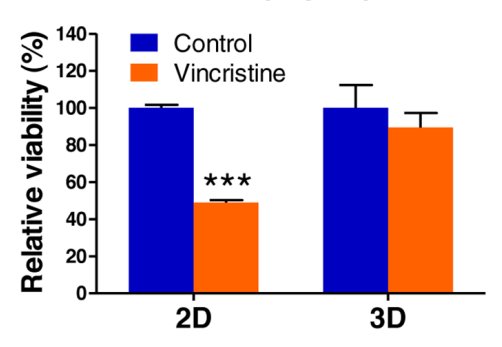

Curcumin

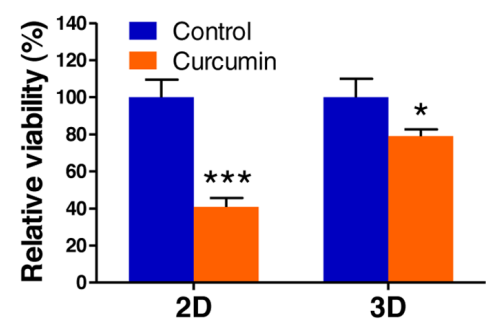

Vincristine

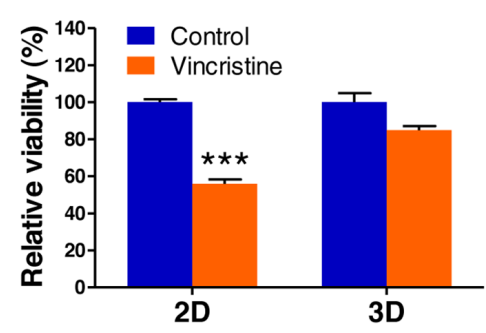

Curcumin

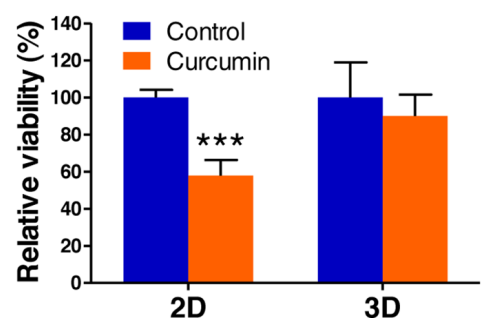

Figure 1: Lymphoma cell responses to chemotherapeutics in 2D and 3D cultures. EL4 (A) and A20 (B) lymphoma cell viabilities in 2D and 3D culture after exposure to doxorubicin, docetaxel, vincristine, 5-FU, resveratrol, and curcumin. Data represent the mean percentage viability $\pm \mathrm{SD}$ of three independent experiments normalized against untreated control cells. ${ }^{*} P<0.05,{ }^{* *} P<0.01$, and ${ }^{* * *} P$ $<0.001$ versus the control. 
agents than cells cultured in 2D were. To evaluate the effects of the 3D microenvironment provided by AmCA hydrogels on the susceptibility to apoptosis caused by doxorubicin, a representative antitumor agent for lymphoma, we seeded EL4 or A20 cells at $1 \times 10^{5}$ cells/ $\mathrm{ml}$ into these hydrogels. On day 7 , when multicellular spheroids were formed in 3D conditions, the cells grown in $2 \mathrm{D}$ or $3 \mathrm{D}$ cultures were exposed to $1 \mu \mathrm{M}$ doxorubicin for $24 \mathrm{~h}$. To determine the mechanism employed in the regulation of apoptosis in the 3D multicellular spheroids, we examined the level of expression of antiapoptotic (Bcl-2 and Bcl-xL) and proapoptotic (Bax) proteins on day 10 .

An annexin V-FITC assay using flow cytometry was performed to evaluate the ability of doxorubicin to induce apoptosis. As shown in Figure 2A, an apoptosis assay showed a significant difference between $2 \mathrm{D}$ and $3 \mathrm{D}$ cultures with regard to the degree of apoptosis induction. The apoptosis rate to doxorubicin was $556.6 \pm 4.5 \%$ (versus $1117.3 \pm 18.1 \%$ for $2 \mathrm{D}$ ) in EL4 cell spheroids and $121.4 \pm 26.7 \%$ (versus $7180.5 \pm 17.3 \%$ for $2 \mathrm{D}$ ) in A20 cell spheroids in comparison to an untreated control condition (considered as $100 \%$ ) grown during the same time. This indicated that the resistance to apoptosis induced by doxorubicin in both cell types was markedly increased in $3 \mathrm{D}$ cultures compared to 2D cultures.

EL4 cells after 3D culture for 10 days in AmCA hydrogels had significantly higher Bcl-2 and Bcl-xL protein levels (7.1-fold and 2.4-fold, respectively) and lower Bax protein levels (0.7-fold) compared to the $2 \mathrm{D}$ controls as assessed by western blotting (Figure 2B). This indicated that the activation of $\mathrm{Bcl}-2$ family proteins (Bcl2 , Bcl-xL, and Bax), the key regulators of apoptosis, is implicated in the molecular mechanism by which the 3D microenvironment in AmCA hydrogels regulates apoptosis in lymphoma cells.

\section{D microenvironment in AmCA hydrogels facilitates tumor progression}

As tumor cells grown in 3D models that efficiently reflect the 3D nature of the in vivo microenvironment are believed to have more malignant phenotypes than those in traditional 2D monolayer cultures, we hypothesized that the multicellular 3D lymphoma spheroids generated in AmCA hydrogels may show expedited progression compared to cells cultured in 2D. To evaluate the effects of the 3D microenvironment provided by AmCA hydrogels on the expression of molecules that play essential roles in tumor progression, we seeded EL4 cells at $1 \times 10^{5}$ cells/ $\mathrm{ml}$ into these hydrogels. On day 10, when multicellular spheroids of these cells were formed in 3D conditions, the expression of Notch receptor genes (Notch-1, -2, -3, and -4), vascular endothelial growth factor (VEGF), and matrix metalloproteinases (MMP-2 and MMP-9) was compared in the cells grown in 2D or 3D cultures.
Activation of the Notch signaling pathway, playing central roles in proliferation and progression of a variety of tumor cell types including lymphoma, was evaluated by RT-PCR to further explore the molecular mechanism by which the 3D microenvironment in AmCA hydrogels regulates tumor aggressiveness in lymphoma cells. As shown in Figure 3A, EL4 cells after 3D culture for 10 days in AmCA hydrogels expressed strikingly elevated gene transcript levels of Notch-1, -2, -3, and -4 (18.6-fold, 2.2-fold, 6.5-fold, and 5.4-fold, respectively) as well as Hes-1 and Hey-1 (58.3-fold and 4.0-fold, respectively), compared to the $2 \mathrm{D}$ controls. To explore the molecular mechanism by which the 3D microenvironment in AmCA hydrogels regulates malignancy in lymphoma cells, the expression levels of MMP and VEGF, critical molecules in tumor cell metastasis and angiogenesis, was determined by western blotting. As shown in Figure 3B, EL4 cells after 3D culture for 7 or 10 days in AmCA hydrogels exhibited strongly enhanced expression of MMP-2 (5.3fold and 16.1-fold, respectively) and MMP-9 (2.9-fold and 4.5-fold, respectively). Additionally, EL4 cells after 3D culture for 10 days in AmCA hydrogels expressed robustly augmented expression of VEGF proteins (2.0-fold for the monomer and 1.4-fold for the dimer) compared to the 2D controls (Figure 3C).

To determine whether 3D culture in AmCA hydrogels enhance the population of $\mathrm{c}-\mathrm{Kit}^{+} / \mathrm{Sca}-1^{+}$lymphoma stem cells, the cells were assessed by flow cytometry. As shown in Figure 4, the 3D microenvironment in AmCA hydrogels profoundly augmented the ratio of lymphoma stem cells by 700.3-fold compared to the control 2D cell culture.

\section{D microenvironment in AmCA hydrogels upregulates multidrug resistance-related gene expression}

Multidrug resistance remains a major obstacle to successful cancer chemotherapy. As tumor cells grown in $3 \mathrm{D}$ models that effectively reflect the 3D nature of the in vivo microenvironment are considered to have more malignant phenotypes than those in traditional 2D monolayer cultures, we hypothesized that the multicellular 3D lymphoma spheroids formed in AmCA hydrogels may display intensified chemoresistancerelated gene expression. To investigate effects of the 3D microenvironment provided by AmCA hydrogels on the expression of multidrug resistance-related genes, we seeded EL4 cells at $1 \times 10^{5}$ cells $/ \mathrm{ml}$ into these hydrogels. On day 10, when multicellular spheroids were formed in $3 \mathrm{D}$ conditions, the expression of the following four important chemoresistance genes was compared in the cells grown in 2D or 3D cultures: (1) MDR1 which is also known as permeability glycoprotein (P-glycoprotein, P-gp) or ATP-binding cassette subfamily B member 1 (ABCB1), (2) multidrug resistance-associated protein 1 (MRP1, ABCC1), (3) breast cancer resistance 
protein (BCRP, ABCG2), and (4) hypoxia-inducible factor- $1 \alpha$ (HIF-1 $\alpha)$. Subsequently, we found that the expression of all the multidrug resistance-related genes tested, i.e., MDR1, MRP1, BCRP, and HIF-1 $\alpha$, were upregulated (3.5-fold, 1.8-fold, 2.3-fold, and 1.9-fold, respectively) in 3D-cultured EL4 cells (Figure 5A). Importantly, minimal expression of MDR1 and BCRP was observed in traditional 2D culture. These results suggest that drug resistance in cells grown in 3D AmCA hydrogel scaffolds could be attributed to increased drug efflux and tumor hypoxia.

To elucidate the molecular mechanism by which the 3D microenvironment in AmCA hydrogels augments multidrug resistance in lymphoma cells, the level of Tiam1 was assessed by RT-PCR. As shown in Figure 5B, expression of molecules involved in the Tiam1 signaling axis, Tiam1, Rac1, and c-Myc, was elevated (19.3-fold, 1.3-fold, and 16.3-fold, respectively) in 3D-cultured EL4 cells. These results suggest that the Tiam1/Rac1 signaling pathway is activated in the multicellular 3D lymphoma spheroids constructed within AmCA hydrogels. Multidrug resistance has also been suggested to be associated with tumor stem cells [23]. As we hypothesized that the lymphoma stem cells present in the multicellular 3D lymphoma spheroids constructed within AmCA hydrogels may be relevant to multidrug resistance, we explored effects of the 3D microenvironment provided by AmCA hydrogels on the expression of Tiam1 and Rac1 genes after isolating the EL4 lymphoma stem cells. Interestingly, the expression of Tiam1 and Rac1 genes was dramatically increased (2.6-fold and 3.4-fold, respectively) in the EL4 stem cells compared to EL4 non-stem cells (Figure 5C).

\section{Potential of the 3D cell culture to simulate tumor growth in vivo}

To explore the relevance of a 3D lymphoma cell culture in AmCA hydrogels to tumor growth in vivo, we compared excised tumor tissue with the 2D- and 3D-lymphoma cell cultures in terms of Tiam1, Rac1, and c-Myc expression. As shown in Figure 6A, the relative expression of Tiam1 mRNA in the EL4 cell spheroids generated in AmCA hydrogels and fresh EL4 tumor were 5.9-fold and 5.6-fold greater than the 2D-cultured EL4 cells, respectively. Moreover, consistent with the Tiam1 expression, Rac1 and c-Myc expression was much higher in the 3D-cultured EL4 cells (2.1-fold and 2.3-fold, respectively) and fresh EL4 tumor (2.2-fold and 2.4-fold, respectively) than the 2D-cultured EL4 cells (Figure 6A). These results were also confirmed by immunofluorescence
A

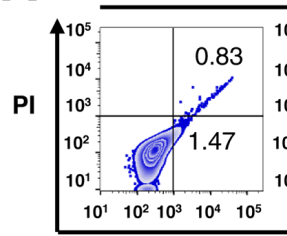

2D
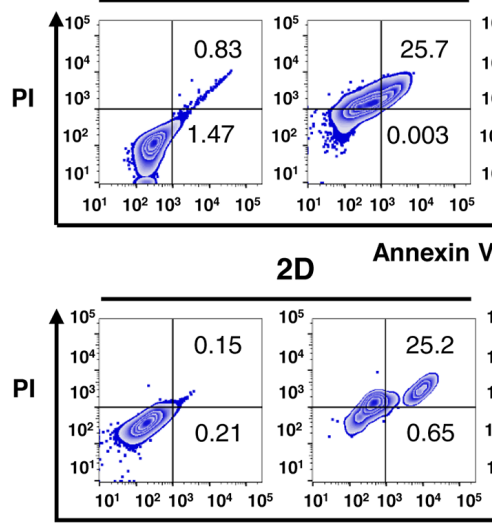

2D
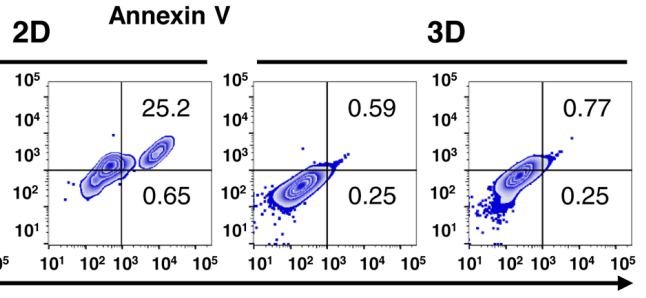

Annexin V
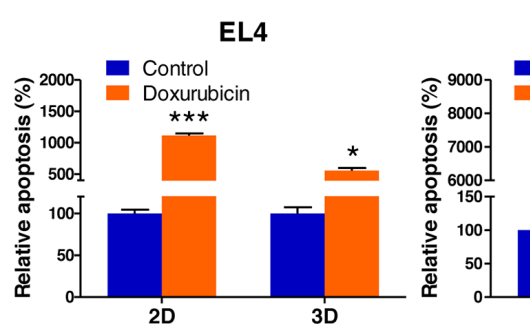

3D

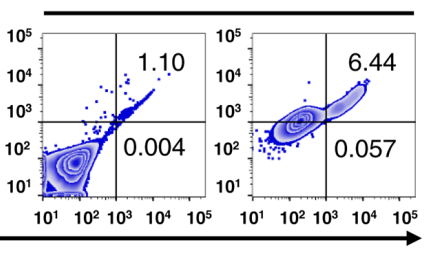

3D

A20
B

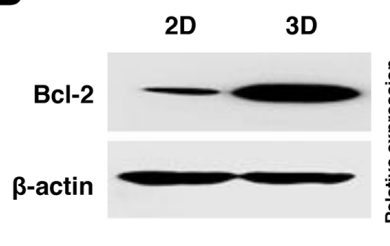

3D
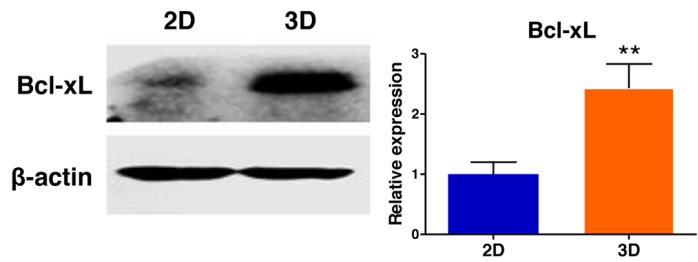

2D
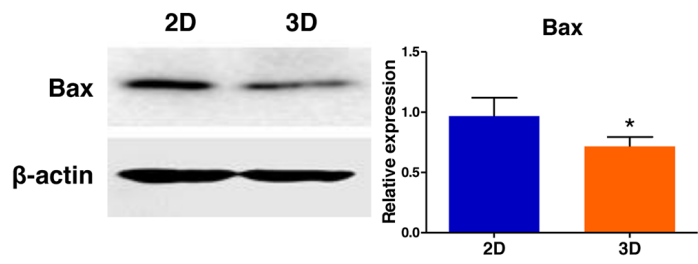

Figure 2: Analysis of apoptotic state in 3D lymphoma spheroids compared to their 2D cultures. (A) Flow cytometric analysis demonstrates increased resistance to apoptosis of EL4 and A20 cells in response to treatment with $1 \mu \mathrm{M}$ doxorubicin (Annexin V positive: apoptotic cells; PI positive: dead cells) in 3D spheroids compared to 2D culture. Apoptosis ratios were calculated from three independent experiments for both cell lines. (B) Western blot analysis of EL4 cells for the expression of apoptosis-regulating proteins in 2D and 3D cultures. Antiapoptotic Bcl-2 and Bcl-xL were upregulated, and proapoptotic Bax was downregulated in 3D cultures than in 2D cultures. Bar graphs depict densitometry quantitation of Bcl-2, Bcl-xL, and Bax protein expression normalized to $\beta$-actin. Data represent the means $\pm \mathrm{SD}$ of three independent experiments. ${ }^{*} P<0.05$ and ${ }^{* *} P<0.01$ versus the control. 
staining of Tiam1 (Figure 6B). These findings confirm that a 3D cell culture in AmCA hydrogels is an exceedingly favorable system to represent in vivo tumor characteristics.

\section{Repression of Tiam 1 expression prevents cell growth in 3D lymphoma spheroids}

To validate inhibition of Tiam 1 expression by NSC23766, a specific inhibitor of the Tiam1/Rac1 signaling module, we performed a western blot assay and immunofluorescence microscopy. These analyses led us to confirm that Tiam1 expression was significantly downregulated by NSC23766 in 3D culture (Figure 7A and B). We next investigated the impact of the Tiam1/ Rac1 inhibitor on the growth of EL4 cells cultured in 3D microenvironments using AmCA hydrogels by phase contrast microscopy (Figure 7C). Inhibition of endogenous Tiam 1 resulted in a marked reduction in the size of EL4 cell spheroids. The average spheroid diameter of EL4 cells in the untreated control group was 105.0, 115.1, and $187.9 \mu \mathrm{m}$ on day 5,7 , and 10 , respectively. After Tiam 1 inhibition, the average spheroid diameter was 50.7, 80.9, and $98.2 \mu \mathrm{m}$ on day 5,7 , and 10 , respectively, suggesting that Tiam1 plays a crucial role in the growth of EL4 cells (Figure 7C).

\section{Combined targeting of Tiam 1 and Notch synergistically increases sensitivity to doxorubicin in the EL4 T and A20 B lymphoma cells}

Despite significant advances in the treatment of lymphoma, drug resistance remains a major cause of treatment failure. To investigate the combined inhibitory effects of Tiam 1 and Notch on resistance to doxorubicin in the 3D-cultured EL4 and A20 cells, we seeded EL4 and A20 cells at $1 \times 10^{5}$ cells $/ \mathrm{ml}$ into these hydrogels. On day 10 , when the cell spheroids were formed in 3D condition, doxorubicin $(1 \mu \mathrm{M})$ was treated in combination with Tiam inhibitor (100 $\mu \mathrm{M}$ NSC23766) or/and Notch inhibitor (5 $\mu \mathrm{M}$ DAPT) in the cells grown in $2 \mathrm{D}$ or $3 \mathrm{D}$ cultures.

A WST-1-based colorimetric cell cytotoxicity assay was employed to evaluate the ability of antitumor agents to induce cytotoxicity. As shown in Figure 8A and B, a cell cytotoxicity assay showed a significant difference between 2D and 3D cultures with regard to antitumor agent sensitivity. In EL4 cells the rates of cell viability in 3D cultures to doxorubicin alone, NSC23766 alone, DAPT alone, doxorubicin pretreated with NSC23766, doxorubicin pretreated with DAPT, combination of NSC23766 with DAPT, and doxorubicin pretreated with combination of NSC23766 and DAPT were $87.8 \pm 0.5 \%$ (versus $44.8 \pm 4.5 \%$ for $2 \mathrm{D}$ ), $75.9 \pm 6.7 \%$ (versus $55.2 \pm$ $10.9 \%$ for $2 \mathrm{D}$ ), $81.7 \pm 3.6$ (versus $87.3 \pm 5.0 \%$ for $2 \mathrm{D}$ ), $60.8 \pm 2.2 \%$ (versus $38.8 \pm 2.5 \%$ for $2 \mathrm{D}$ ), $56.6 \pm 9.5 \%$ (versus $39.6 \pm 4.4 \%$ for $2 \mathrm{D}$ ), $63.8 \pm 4.6 \%$ (versus 49.9 $\pm 1.0 \%$ for $2 \mathrm{D}$ ), and $23.9 \pm 11.2 \%$ (versus $34.5 \pm 8.7 \%$ for $2 \mathrm{D}$ ), respectively (Figure 8A). An untreated condition (considered as 100\%) grown during the same time served as the control. A similar effect was also observed with A20 cell spheroids; the rates of cell viability in $3 \mathrm{D}$ cultures to doxorubicin alone, NSC23766 alone, DAPT alone, doxorubicin pretreated with NSC23766, doxorubicin pretreated with DAPT, combination of NSC23766 with DAPT, and doxorubicin pretreated with combination of NSC23766 and DAPT were $74.4 \pm 8.1 \%$ (versus $47.3 \pm$ $2.6 \%$ for $2 \mathrm{D}$ ), $76.9 \pm 7.7 \%$ (versus $62.4 \pm 0.5 \%$ for $2 \mathrm{D}$ ), $80.7 \pm 18.0$ (versus $84.7 \pm 1.5 \%$ for $2 \mathrm{D}$ ), $61.9 \pm 19.4 \%$ (versus $57.9 \pm 0.8 \%$ for $2 \mathrm{D}$ ), $54.6 \pm 17.6 \%$ (versus $72.6 \pm$ $1.8 \%$ for $2 \mathrm{D}$ ), $69.2 \pm 15.5 \%$ (versus $58.9 \pm 3.6 \%$ for $2 \mathrm{D}$ ), and $30.7 \pm 4.2 \%$ (versus $44.2 \pm 1.6 \%$ for $2 \mathrm{D}$ ), respectively (Figure 8B).

The levels of increased sensitivity to doxorubicin in the group pretreated with either the Tiam1/Rac1 inhibitor or the Notch inhibitor compared to the group treated with doxorubicin alone were significantly higher in $3 \mathrm{D}$ than in 2D condition in both cell types (Figure 8). The levels of increased sensitivity to doxorubicin in the group pretreated with a combination of Tiam1 and Notch inhibitors compared to the group pretreated with either the Tiam1/ Rac1 inhibitor or the Notch inhibitor were much higher in $3 \mathrm{D}$ than in $2 \mathrm{D}$ condition in both cell types (Figure 8). The augmented sensitivity to doxorubicin by combined pretreatment with Tiam1 and Notch inhibitors was more prominent in 3D lymphoma spheroids compared to the 2D-cultured cells in both cell types (Figure 8).

\section{DISCUSSION}

Unlike 2D cell culture, 3D cell culture has the potential to make an innovative breakthrough in the understanding of tumor biology, metastasis, oncotargets, biomarkers, drug discovery, and targeted therapies [24]. An accumulating body of evidence indicates that multicellular 3D spheroids fabricated in properly assembled hydrogels can serve as a favorable carcinoma model, and their spatial 3D organization offers collective properties of a cell population that may profoundly affect important tumor cell behavior such as tumor aggressiveness and chemotherapy resistance [25]. Despite an intense interest in $3 \mathrm{D}$ tumor models, there have been only a few attempts to develop 3D lymphoma culture systems [26]. Birgersdotter et al. [27] used self-assembling peptide-based hydrogels for the construction of a 3D Hodgkin lymphoma cell culture model and found that the 3D cell culture induced a more tumor-related gene expression profile compared to 2D cell culture. Caicedo-Carvajal et al. [28] tested the efficacy of a 3D lymphoma cell culture using polystyrene polymer scaffolds and demonstrated that the $3 \mathrm{D}$ culture model had a higher proliferative rate than the $2 \mathrm{D}$ culture model. Gravelle et al. [29] demonstrated that multicellular aggregates of follicular lymphoma cells, obtained by 
a simple 3D cell culture technique, show different cell properties such as proliferation, signaling pathway, cellular defenses, sensitivity to immune effectors, and resistance to doxorubicin and bendamustine compared to $2 \mathrm{D}$ cell culture. In addition, these multicellular aggregates of follicular lymphoma cells also exhibited different responses to antibody-based therapeutics between $3 \mathrm{D}$ and $2 \mathrm{D}$ cultures [25]. These results support the use of 3D multicellular aggregates of follicular lymphoma cells for the testing of therapeutic agents in follicular lymphoma. Recently, Tian et al. [30] synthesized integrin-specific ligand functionalized 3D hydrogel organoids of malignant $\mathrm{B}$ and $\mathrm{T}$ cell tumors using maleimide functionalized 4-arm polyethylene glycol and thiolated cross-linkers. They demonstrated that the $3 \mathrm{D}$ culture exhibited enhanced proliferation, clustering, and drug resistance to doxorubicin and a histone deacetylase inhibitor, panobinostat [30]. Furthermore, it was found that the $3 \mathrm{D}$ microenvironment in diffuse large $\mathrm{B}$ cell lymphomas upregulated the expression level of B cell receptor, which is involved in the survival of $\mathrm{B}$ lymphoma cells [30]. While these studies have provided evidence that lymphoma cells grown in 3D behave in a way reminiscent of the in vivo tissue microenvironment of malignant $\mathrm{B}$ and $\mathrm{T}$ cell lymphoma, further studies are necessary for a more comprehensive assessment of diverse aspects of potential 3D lymphoma models.

In this study, we established an efficient 3D $\mathrm{T}$ and B cell lymphoma culture model using AmCA hydrogels,

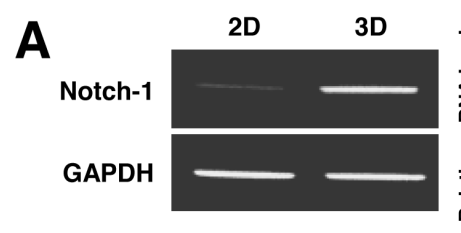

2D

3D

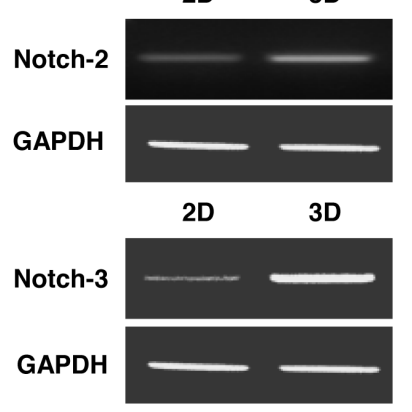

2D

3D

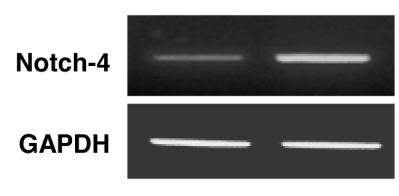

2D

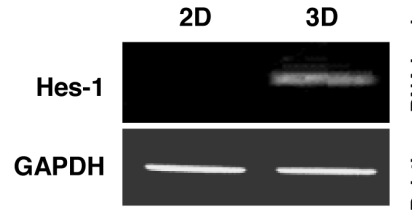

2D

3D

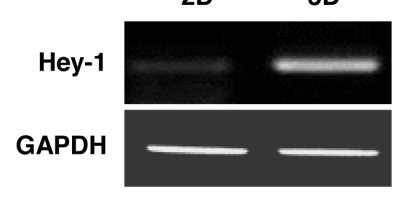

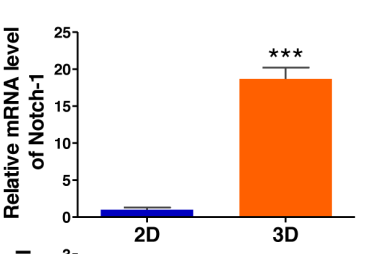
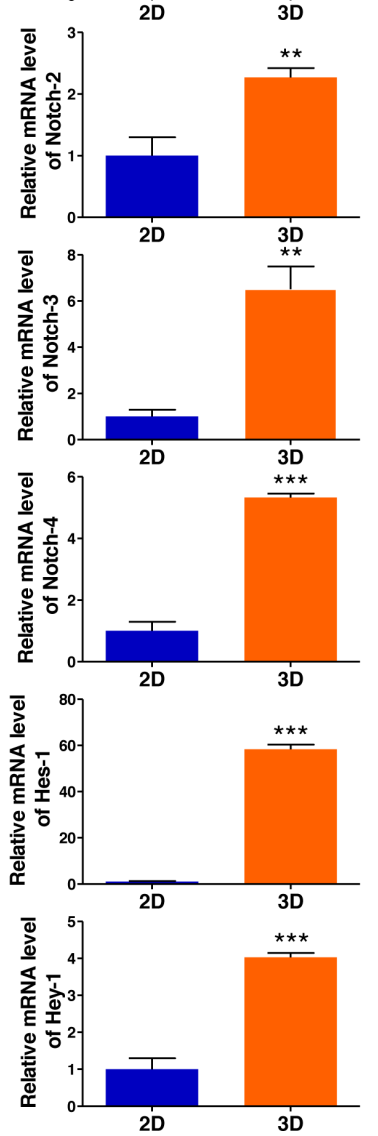

B
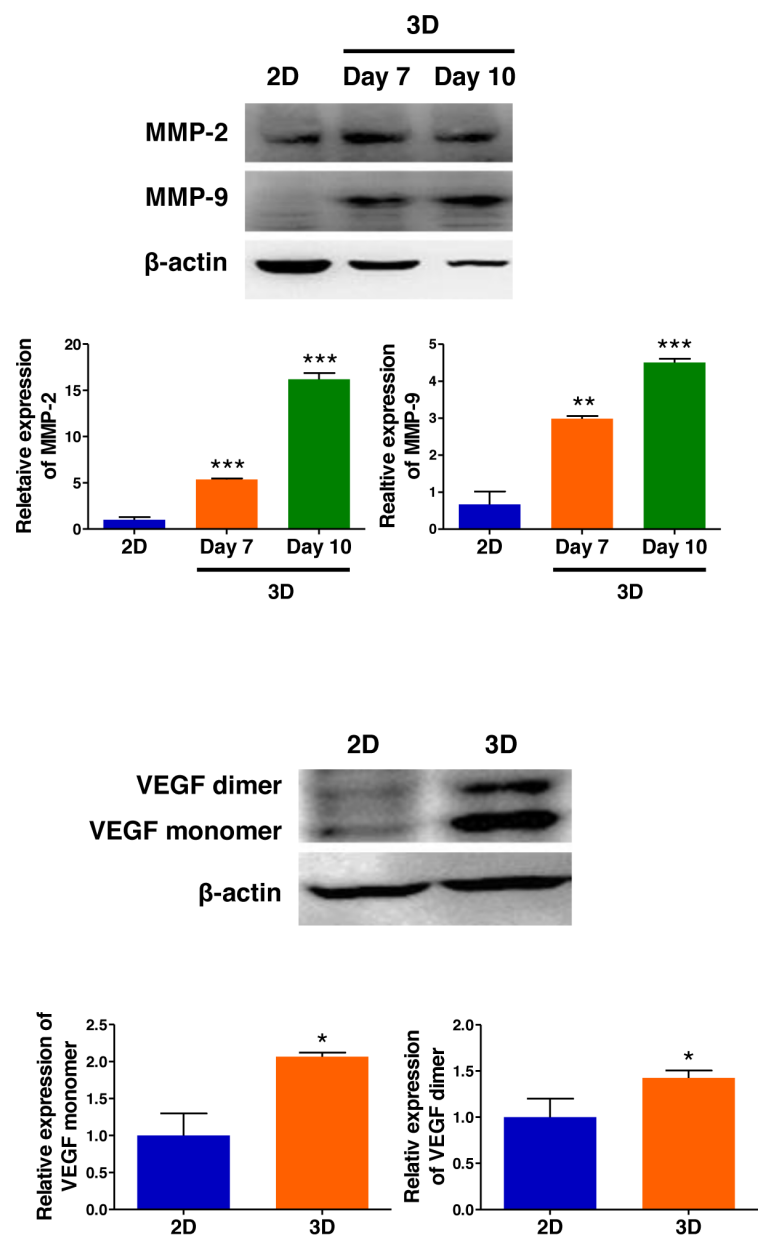

Figure 3: 3D microenvironment in AmCA hydrogels enhances the expression of tumor aggressiveness factors in 3D lymphoma spheroids compared to their 2D cultures. (A) RT-PCR demonstrates upregulated gene expression of Notch (Notch-1, $-2,-3$, and -4) and its downstream molecules (Hes-1 and Hey-1) important in tumor promotion and progression in 3D spheroids compared to 2D culture. Bar graphs depict densitometry quantitation of Notch, Hes-1, and Hey-1 mRNA expression normalized to GAPDH mRNA. Western blot demonstrates upregulated expression of (B) MMPs (MMP-2 and MMP-9) and (C) VEGF proteins important in tumor progression and metastasis in 3D spheroids compared to 2D culture. Bar graphs depict densitometry quantitation of MMP-2, MMP-9, and VEGF protein expression normalized to $\beta$-actin. Data represent the means $\pm \mathrm{SD}$ of three independent experiments. ${ }^{*} P<0.05$, ${ }^{* *} P<0.01$, and ${ }^{* * *} P<0.001$ versus the control. 
and elucidated that increased resistance against antitumor agents in the 3D EL4 T and A20 B lymphoma models may be attributed to high levels of drug resistance gene expression, multiple perturbations in the apoptosis pathway, elevated levels of factors associated with tumor aggressiveness, hypoxia induction, augmented angiogenic potential, and enhanced tumor stemness. Importantly, the salient feature of our data is that combined treatment with inhibitors of Tiam 1 and Notch was found to synergistically increase sensitivity to doxorubicin in EL4 and A20 cells than either treatment alone. It is also noteworthy that EL4 cells expressed higher levels of Tiam 1 in the 3D culture and fresh EL4 tumor compared to the 2D culture, while there was no significant difference in the expression level of Tiam1/Rac1 between the 3D culture and fresh in vivo tumor. This suggests that our $3 \mathrm{D}$ lymphoma model precisely reflects the essential characteristics of an in vivo tumor including drug resistance, and thereby provides a preferential drug screening platform that can produce more clinically relevant results.

It has previously been reported that Tiam 1 is highly expressed in lymphoma, leukemia, and many solid tumors including pancreatic, breast, bladder, lung, colorectal, gastric, liver, ovarian, prostate, and neck squamous cell cancer [17, 31, 32]. Evidence has been accumulating that Tiam1 plays a critical role in tumor initiation, promotion, and progression of various tumor cells including breast, colorectal, skin, and liver cancer $[18,19]$. It was recently found that Tiam1 promotes proliferation, invasion, and metastasis in oral squamous cell carcinoma cells by binding with Semaphorin 4D [33]. It was also shown that Tiam 1 expression is strongly associated with grade and outcome in ovarian carcinoma, and it may serve as a useful molecular marker for prognosis and clinical management [34]. Moreover, the Tiam1/Rac1 signaling axis contributes to tumorigenic progression in triple-negative breast cancer by mediating the acquisition of integrin-directed metastasis-associated tumor cell phenotypes [35]. Despite many studies on the role of Tiam1 in various types of tumors, surprisingly little information is available about the role of Tiam1 in lymphoma. Tiam1 expression was observed to be higher in extranodal NK/T-cell lymphoma tissue than the control [36]. Cordo-Russo et al. [21] showed that lymphoma cell lines resistant to chemotherapeutic agents presented a higher migratory capacity towards hyaluronan in vitro as well as a higher Tiam1 expression than the sensitive cell line, suggesting the possible implications of Tiam1 for the chemoresistance in lymphoma. Notably, we confirmed in the present study that Tiam1 is involved in chemoresistance against doxorubicin in EL4 T and A20 B lymphoma cells.

Multidrug resistance, a complex biological phenomenon whereby tumor cells become resistant to a wide spectrum of drugs with different structures or cellular
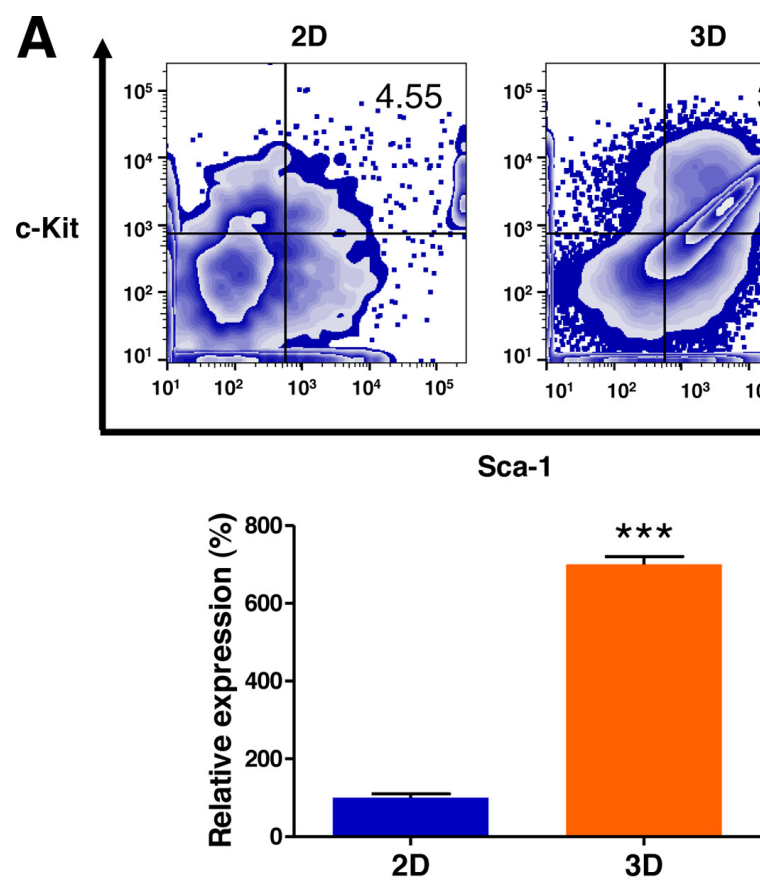

3D

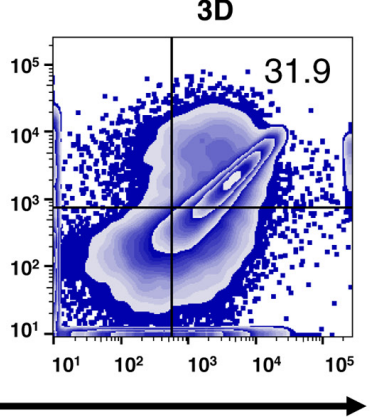

B
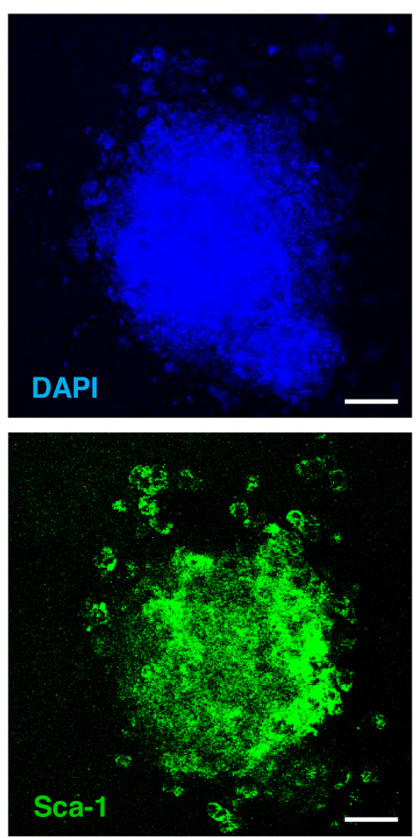
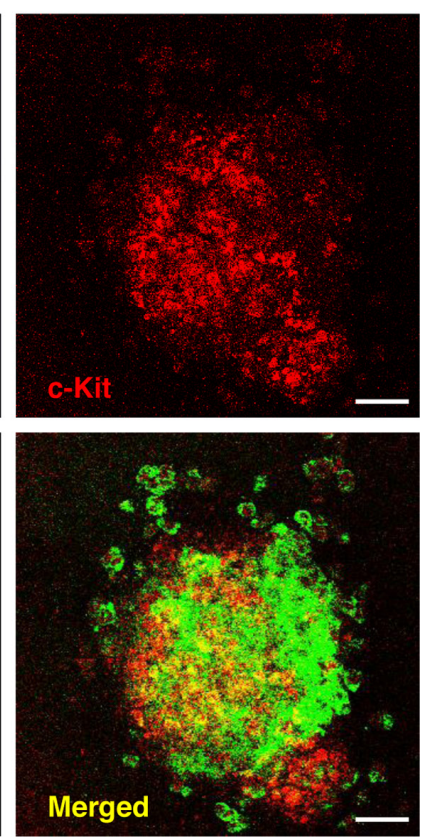

Figure 4: 3D microenvironment in AmCA hydrogels augments the lymphoma stem cell population in 3D lymphoma spheroids compared to their 2D cultures. (A) Flow cytometric analysis of EL4 cells for the expression of the lymphoma stem cell markers c-Kit and Sca-1. Percentages of the cell population expressing c-Kit ${ }^{+} / \mathrm{Sca}-1^{+}$in EL4 cells cultured under 2D and 3D conditions are presented. Data represent the means $\pm \mathrm{SD}$ of three independent experiments. ${ }^{* * *} P<0.001$ versus the control. (B) Confocal microscopic analysis of EL4 cells for the expression of c-Kit and Sca-1. Immunofluorescence images show the distribution features of lymphoma stem cells in the spheroids. Scale bar, $40 \mu \mathrm{m}$. 
targets, is a common cause of failure in chemotherapy. It is generally accepted that the overexpression of the multidrug resistance proteins of tumor cells such as MDR1, MRP1, BCRP, and HIF-1 $\alpha$ mediate multidrug resistance, although its mechanism is not yet clear [37-39]. The hypoxic microenvironment of the tumor tissue as well as its related characteristics such as low nutrient supply and low $\mathrm{pH}$ have been suggested to upregulate the expression of multidrug resistance proteins through specific cellular signaling pathways [39-41]. We demonstrated that our lymphoma models efficiently mimic the real tumor microenvironment since it has been reported that the size of multicellular spheroids more than about $100 \mu \mathrm{m}$ in diameter contain an internal hypoxic zone caused by limited distribution of oxygen, nutrients and metabolites, and a necrotic core $[42,43]$. Although tumor cells grown in 2D culture have contributed tremendous amounts of knowledge regarding the mechanism of cancer, this system has unfortunately resulted in a $95 \%$ drug failure rate [44]. Thus, 3D models with customized microenvironments yield the greatest value in the vast field of biomedical research, especially including studies of tumor biology and establishment of therapeutic screens. Moreover, in antitumor drug testing, the 3D organization of the tumor mass and the complex 3D ECM network architecture have important advantages, as the $2 \mathrm{D}$ cultures do not effectively recapitulate the multidrug resistanceconducive environment $[45,46]$.

The Notch pathway is one of the most intensively studied candidate therapeutic targets for tumor cells, as Notch signaling is critical for cell proliferation, aggressiveness, and chemoresistance as well as stem cell
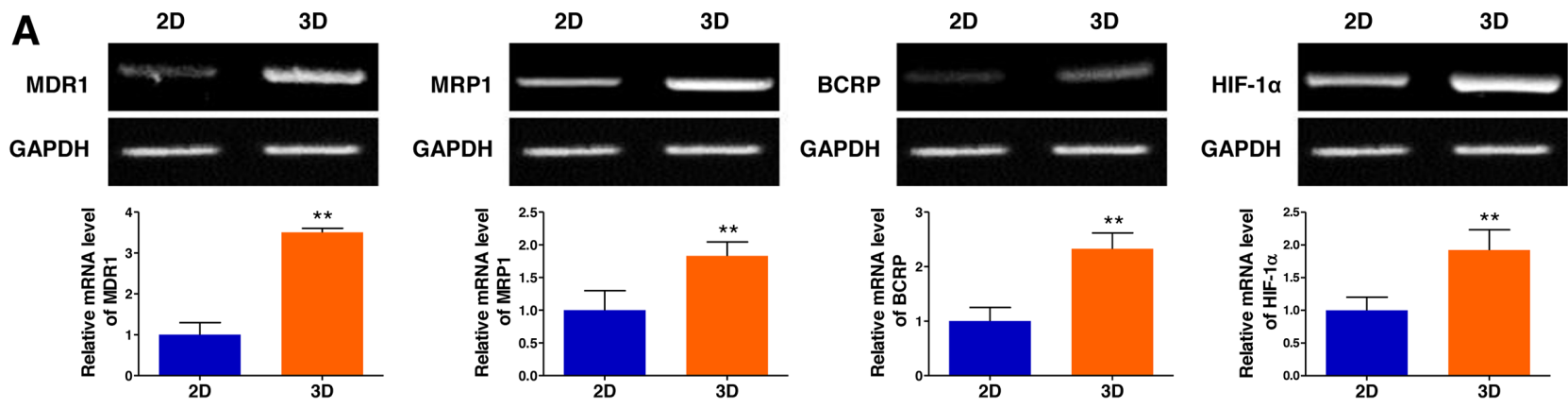

B
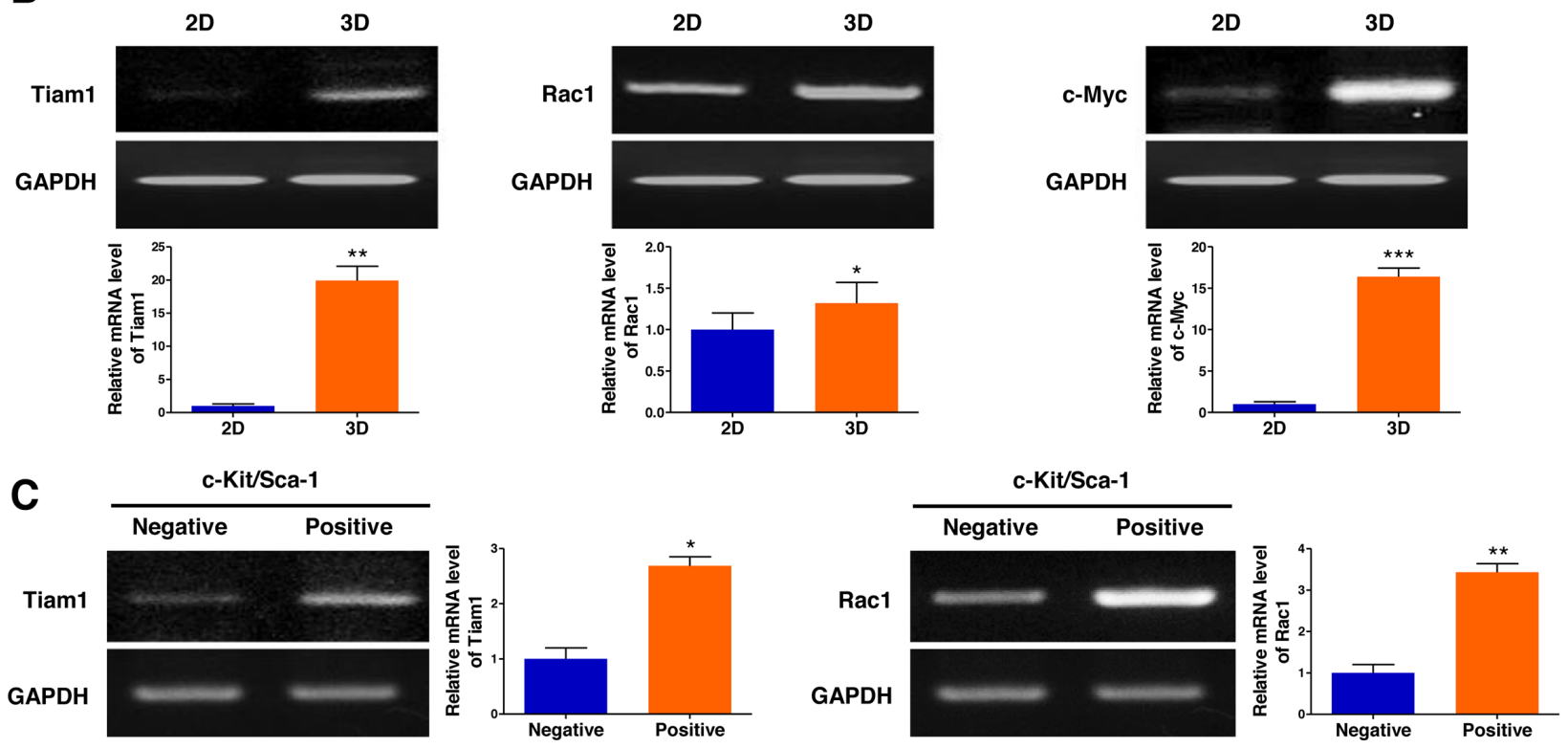

Figure 5: 3D microenvironment in AmCA hydrogels elevates the expression of multidrug resistance-related genes in 3D lymphoma spheroids compared to their 2D cultures. (A) RT-PCR demonstrates upregulated expression of MDR1, MRP1, BCRP, and HIF-1 $\alpha$ genes important in promoting malignancy and multidrug resistance in 3D spheroids compared to 2D culture. Bar graphs depict densitometry quantitation of MDR1, MRP1, BCRP, and HIF-1 $\alpha$ mRNA expression normalized to GAPDH mRNA. (B) RTPCR demonstrates upregulated expression of Tiam1, Rac1, and c-Myc genes important in tumor progression and chemoresistance in 3D spheroids compared to 2D culture. Bar graphs depict densitometry quantitation of Tiam1, Rac1, and c-Myc mRNA expression normalized to GAPDH mRNA. (C) RT-PCR analysis of EL4 cells for the expression of Tiam1 and Rac1 genes by c-Kit ${ }^{+} / \mathrm{Sca}^{-1}{ }^{+}$stem cells and c-Kit$/^{-}$ Sca-1' non-stem cells. Bar graphs depict densitometry quantitation of Tiam1 and Rac1 mRNA expression normalized to GAPDH mRNA. Data represent the means $\pm \mathrm{SD}$ of three independent experiments. ${ }^{*} P<0.05,{ }^{* *} P<0.01$, and ${ }^{* * *} P<0.001$ versus the control. 
propagation in diverse types of primary and metastatic tumors [47]. The molecular mechanisms underlying acquisition of chemoresistance coordinated by Notch signaling are believed to involve the induction of the epithelial-mesenchymal transition (EMT), formation of tumor stem cells, upregulated expression of MDR such as the MDR1, MRP1, BCRP, and HIF-1 $\alpha$, and the enhanced production of oncogenic microRNAs (miRNAs) [4850]. Thus, many scientists are trying to develop targeted therapeutic strategies to inhibit the Notch pathway for the successful treatment of human malignancies.

Tumor stem cells, present in different types of malignancies, appear to share common features including a state of relative quiescence and a self-renewal capacity in the context of preferentially asymmetric divisions [51]. Furthermore, they are reported to be highly resistant to chemotherapeutic treatments or irradiation, possibly due to their high DNA repair capacity and to the expression of multidrug resistance [52]. Hence, development of novel therapies targeted at tumor stem cells holds great hope for the treatment of multidrug-resistant and metastatic tumors. Interestingly, they preferentially tend to grow in spheroidlike structures in vitro likely by alterations in their characteristics including loss of cell polarity or defective interaction with ECM components, although its exact mechanism remains elusive $[53,54]$. Different types of matrices have also been used to promote their maintenance or differentiation [55-56]. Our data indicate that the AmCA hydrogels provide a favorable $3 \mathrm{D}$ culture platform for expansion of cells characterized by lymphoma stem cell-like features, and they can be very useful in the study of lymphoma stem cells as well as in the development of a new and potential therapeutic strategy for lymphoma.

In conclusion, we developed an effective in vitro 3D lymphoma cell culture system using AmCA hydrogel scaffolds that can imitate the in vivo 3D lymphoma microenvironment. Lymphoma cells grown in these 3D culture system exhibited biochemical and physiological features including (1) enhanced chemotherapy resistance, (2) suppressed rate of apoptosis, (3) upregulated expression of multidrug resistance-related genes (MDR1, MRP1, BCRP, and HIF-1 $\alpha$ ), (4) elevated levels of key molecules associated with tumor progression and malignancy including apoptosis-regulating molecules (Bcl-2, Bcl-xL, and Bax), Notch (Notch-1, -2, -3 and -4) and its downstream molecule (Hes-1 and Hey-1), VEGF, and MMPs (MMP-2 and MMP-9), and (5) enrichment of a lymphoma stem cell population by about 700 -fold, compared to 2D-based conventional suspension cell culture. Importantly, Tiam1 as a potential biomarker
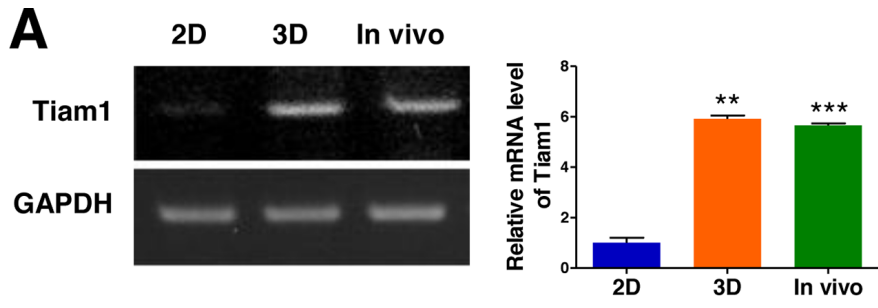

2D

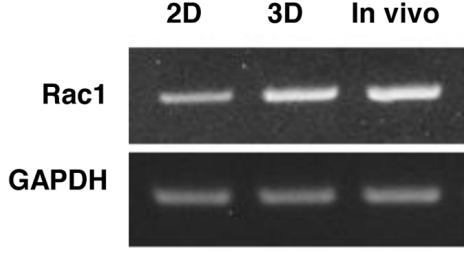

2D

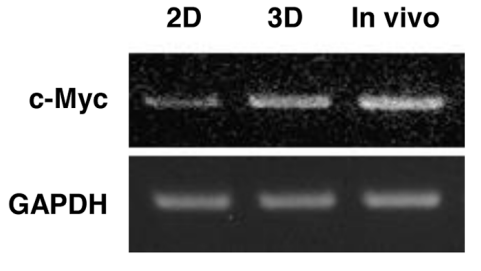

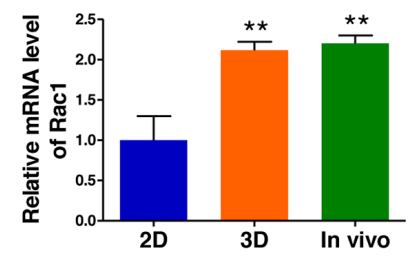

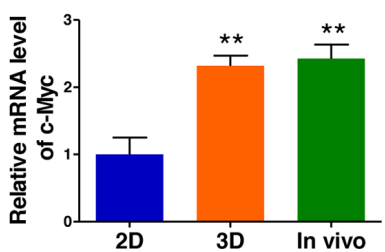

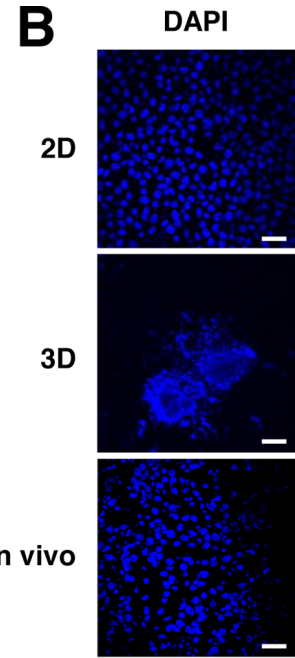
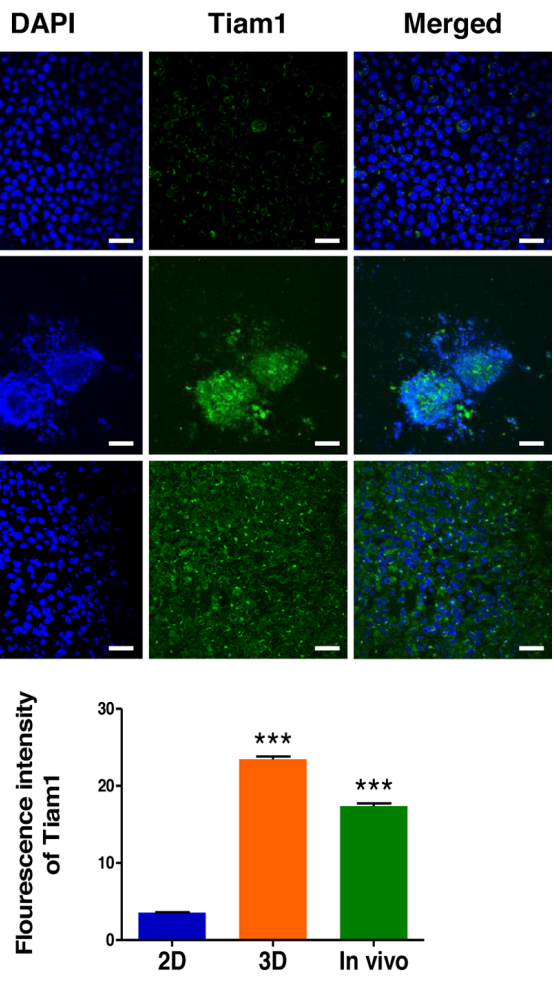

Figure 6: Expression of Tiam1, Rac1, and c-Myc in 2D- and 3D-cultured EL4 cells and their in vivo tumor tissue. (A) RTPCR demonstrates upregulated expression of Tiam1, Rac1, and c-Myc genes in 3D spheroids compared to 2D culture. EL4 cells expressed higher levels of Tiam1 in the 3D culture and fresh EL4 tumor than in the 2D culture, with no significant difference in the expression level of Tiam1/Rac1 between the 3D culture and fresh in vivo tumor. Bar graphs depict densitometry quantitation of Tiam1, Rac1, and c-Myc mRNA expression normalized to GAPDH mRNA. (B) Immunofluorescence images also show that EL4 cells expressed higher levels of Tiam1 in the 3D culture and fresh EL4 tumor than in 2D culture. The Tiam1 staining intensities were measured using ImageJ software. Data represent the means $\pm \mathrm{SD}$ of three independent experiments. Scale bar, $40 \mu \mathrm{m} .{ }^{*} P<0.05,{ }^{* *} P<0.01$, and ${ }^{* * *} P<0.001$ versus the control. 
of tumor initiation and progression, metastasis, and chemoresistance in many tumor cells was activated in our 3D lymphoma model. Remarkably, we identified two synergistic therapeutic oncotargets, Tiam1 and Notch, as a strategy to combat resistance against doxorubicin in EL4 $\mathrm{T}$ and A20 B lymphoma. Therefore, our data suggest that our 3D lymphoma model is a promising in vitro research platform to study lymphoma biology as well as screen new anti-lymphoma therapeutics.

\section{MATERIALS AND METHODS}

\section{Cell line, culture maintenance, and materials}

The biomaterials used for fabricating hydrogels were sodium alginate (W201502, Sigma-Aldrich, St. Louis, MO, USA), agarose (32802, high melting agarose, Affymetrix, Cleveland, OH, USA), PBS without $\mathrm{CaCl}_{2}$ and $\mathrm{MgCl}_{2}$ (D5652, Sigma-Aldrich), bovine serum albumin (A9647, BSA, Sigma-Aldrich), and marine collagen (MC) extracted from tilapia fish scales (Geltech, Busan, Korea). 4,6-Diamidino-2-phenylindole (DAPI) was purchased from Vector Laboratories (H-1200, Burlingame, CA, USA). For the tumor cell lines, EL4 cells (TIB-39TM; a mouse thymic $\mathrm{T}$ cell lymphoma cell line) and A20 cells (TIB208 ${ }^{\text {TM; }}$ a mouse B cell lymphoma cell line) were purchased from the American Type Culture
Collection (ATCC, Manassas, VA, USA). Both cell types were cultured in RPMI-1640 medium (11875-093, Invitrogen, Carlsbad, CA, USA) containing 10\% FBS, $100 \mathrm{IU} / \mathrm{ml}$ penicillin, and $100 \mu \mathrm{g} / \mathrm{ml}$ streptomycin at 37 ${ }^{\circ} \mathrm{C}$ in a $5 \% \mathrm{CO}_{2}$ incubator. All cell culture reagents were obtained from Gibco/Thermo Fisher Scientific (Carlsbad, CA, USA) unless specified otherwise.

\section{Synthesis of hydrogels for $3 D$ cell culture}

AmCA hydrogels for 3D cell culture were prepared as previously described by our group [7]. Briefly, sodium alginate was dissolved at $50 \mathrm{mg} / \mathrm{ml}$ in deionized water by constant stirring overnight at room temperature to prepare a 5\% alginate stock solution and then autoclaved before use. MC was completely dissolved by vortexing in nuclease-free water at room temperature to make a $25 \%$ stock solution. High melting point agarose was added at $20 \mathrm{mg} / \mathrm{ml}$ to deionized water, heated on a hot plate, and stirred occasionally until completely dissolved to make a $2 \%$ agarose stock solution. Then, $337 \mu$ of cells resuspended in culture medium $\left(1 \times 10^{5}\right.$ cells $\left./ \mathrm{ml}\right)$ were mixed with $200 \mu \mathrm{l}$ of $5 \%$ sodium alginate solution in a $1.5 \mathrm{ml}$ microcentrifuge tube at room temperature. This solution was then combined with $400 \mu \mathrm{l}$ of $25 \% \mathrm{MC}$ stock solution at room temperature to obtain $10 \% \mathrm{MC} / 1 \%$ alginate solutions containing cells. These cell suspensions
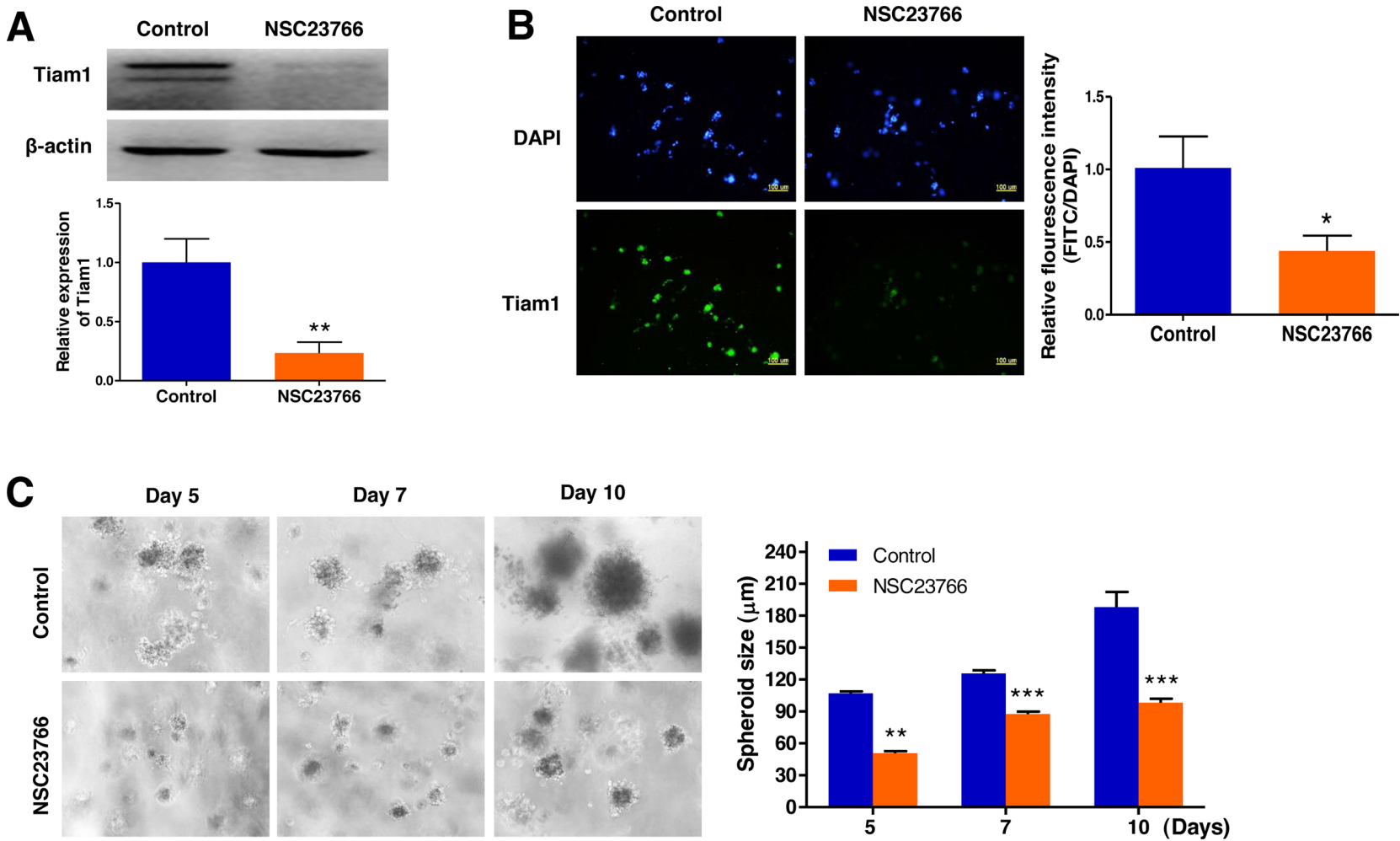

Figure 7: Repression of Tiam1 expression prevents cell growth in 3D lymphoma spheroids. (A) Western blot and (B) immunofluorescence microscopy demonstrates the strong inhibition of Tiam1 expression by NSC23766 in 3D spheroids. (C) Phase contrast microscopy demonstrates a marked reduction in the size of EL4 cell spheroids by inhibition of endogenous Tiam1. Data represent the means \pm SD of three independent experiments. ${ }^{*} P<0.05,{ }^{* *} P<0.01$, and ${ }^{* * *} P<0.001$ versus the control. 
were then blended carefully with $62.5 \mu$ l of $2 \%$ agarose solution at $35-40^{\circ} \mathrm{C}$ to avoid cell damage. The final concentrations of agarose, $\mathrm{MC}$, and alginate in the AmCA solution were $0.125 \%, 10 \%$, and $1 \%$, respectively.

For the gelation of hydrogel solutions containing cells, they were vortexed briefly, pipetted into $1 \mathrm{ml}$ syringes, and finally incubated at $4^{\circ} \mathrm{C}$ for $5-10 \mathrm{~min}$. The gelled hydrogels were then transferred to the wells of 24-well plates containing $1 \mathrm{ml}$ of culture medium and incubated at $37^{\circ} \mathrm{C}$ for the desired time. Media were refreshed every 2 days.

\section{Cell spheroid-based antitumor drug test}

To conduct antitumor drug tests against the cancer cell spheroids, doxorubicin (5927S, Cell Signaling, Danvers, MA, USA), docetaxel (01885, Sigma-Aldrich), resveratrol (R5010, Sigma-Aldrich), 5-FU (F6627, Sigma-Aldrich), vincristine (V8879, Sigma-Aldrich), and curcumin (C7727, Sigma-Aldrich) were used as antitumor agents in the present study. After spheroid formation, the drug-free culture media was replaced with $1 \mu \mathrm{M}$ doxorubicin, $0.5 \mu \mathrm{M}$ docetaxel, $100 \mu \mathrm{M}$ resveratrol, $5 \mu \mathrm{M}$ 5-FU, $1 \mu \mathrm{M}$ vincristine, $10 \mu \mathrm{M}$ curcumin, $100 \mu \mathrm{M}$ Tiam1/ Rac1 inhibitor (2221, NSC23766, Tocris Bioscience, Bristol, UK), and $5 \mu \mathrm{M} \mathrm{N}-[\mathrm{N}-(3,5$-difluorophenacetyl)L-alanyl]-S-phenylglycine t-butyl ester (2634, DAPT, an inhibitor of the $\gamma$-secretase complex, Tocris Bioscience) in RPMI-1640. The efficacy of combination treatment of doxorubicin with either Tiam 1 inhibitor or $\gamma$-secretase inhibitor, or with both agents was examined. Control groups of conventional 2D-cultured cells were treated with the same concentrations of these antitumor agents after reaching $60 \%$ to $80 \%$ confluence. After $24 \mathrm{~h}$ treatment,
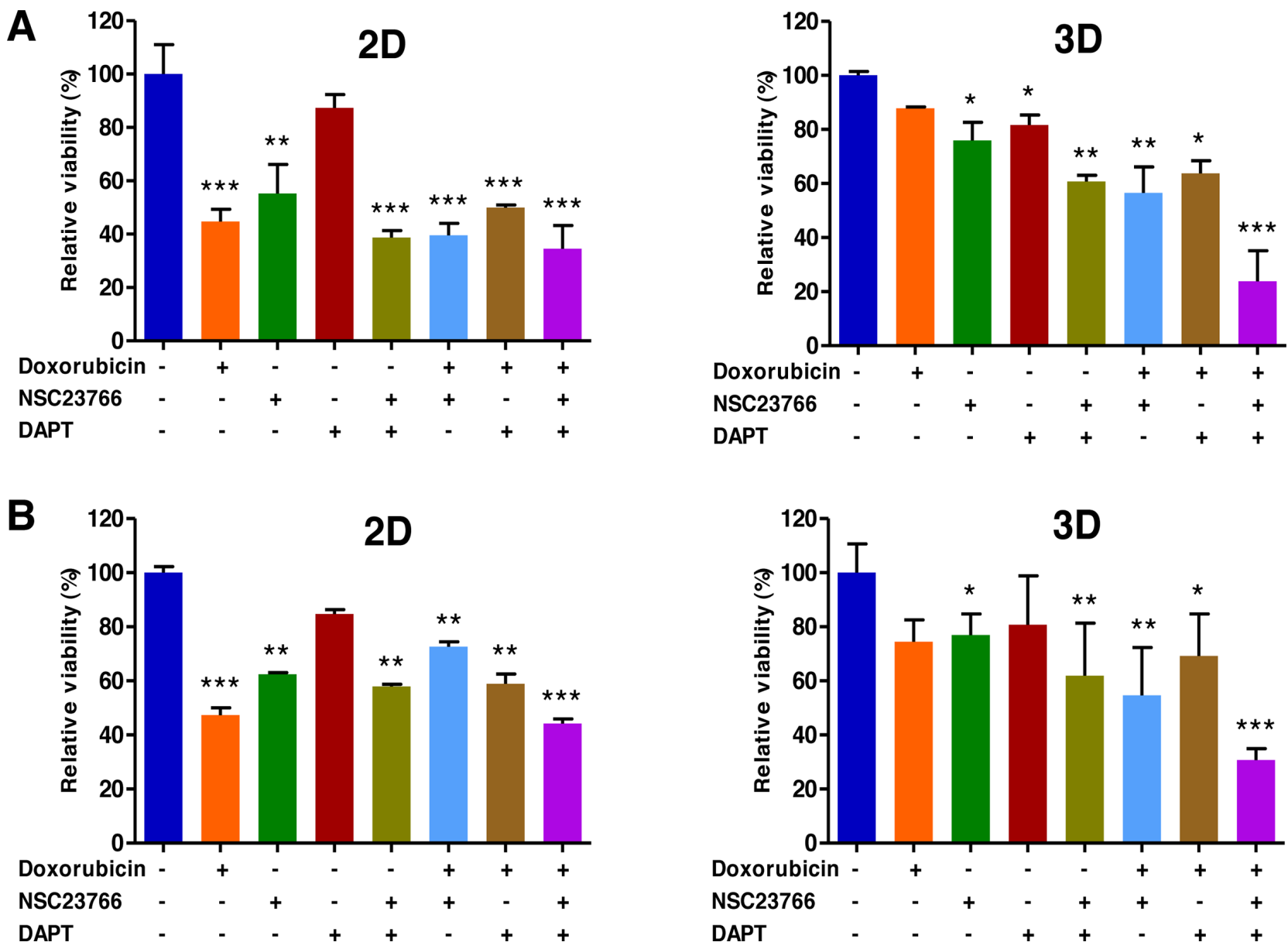

Figure 8: Combined targeting of Tiam 1 and Notch synergistically increase sensitivity to doxorubicin in 2D- and 3D-cultured EL4 T (A) and A20 (B) B lymphoma cells. (A) WST-1-based colorimetric cell cytotoxicity assay demonstrates a significant difference between 2D and $3 \mathrm{D}$ cultures with regard to doxorubicin sensitivity. The levels of increased sensitivity to doxorubicin in the group pretreated with either the Tiam1/Rac1 inhibitor or the Notch inhibitor compared to the group treated with doxorubicin alone are significantly higher in 3D than in 2D condition in both cell types. The levels of increased sensitivity to doxorubicin in the group pretreated with a combination of Tiam1 and Notch inhibitors compared to the group pretreated with either the Tiam1/Rac1 inhibitor or the Notch inhibitor are much higher in 3D than in 2D condition in both cell types. Remarkably, the augmented sensitivity to doxorubicin by combined pretreatment with Tiam1 and Notch inhibitors is more prominent in 3D lymphoma spheroids compared to the 2D-cultured cells in both cell types. Data represent the means \pm SD of three independent experiments. ${ }^{*} P<0.05,{ }^{* *} P<0.01$, and ${ }^{* * *} P<0.001$ versus the control. 
cell viability was assessed using the EZ-Cytox assay (EZ-3000, Daeil Lab Service, Seoul, Korea) in 96-well microtiter plates by reading at an OD of $450 \mathrm{~nm}$.

\section{In vivo EL4 lymphoma model}

Male syngeneic C57BL/6 $\left(\mathrm{H}-2 \mathrm{~K}^{\mathrm{b}}\right)$ mice were purchased from Dae Han Bio Link (Seoul, Korea). All animals were housed at 4-5 mice per cage and maintained under a $12 \mathrm{~h} \mathrm{light/dark} \mathrm{cycle} \mathrm{at} \mathrm{a} \mathrm{temperature} \mathrm{of} \mathrm{20-22}$ ${ }^{\circ} \mathrm{C}$ with humidity $64 \pm 15 \%$ in a filtered laminar air flowcontrolled, specific pathogen-free facility. All mice were given irradiated food and sterile water ad libitum. Mice were allowed to adjust to their environment for 1 week and used at 8-10 weeks of age for implantation of tumor cells. $1 \times 10^{6}$ EL4 cells were subcutaneously inoculated in the both left and right flanks of the mice $(n=5)$. Two weeks after injection, the mice were sacrificed, and the excised tumors were processed for experiments. Animal care and all experimental procedures were conducted in accordance with the "Guide for Animal Experiments edited by the Korean Academy of Medical Sciences."

\section{Extraction of RNA and reverse transcription polymerase chain reaction for $3 \mathrm{D}$ hydrogels}

For the tumor tissue, samples were transferred to tubes containing $1 \mathrm{ml}$ TRIzol $^{\circledR}$ Reagent (A33251, Invitrogen). Upon completion of the harvest procedure, the homogenates were transferred to empty RNase-free falcon tubes stored on ice. The homogenates were extracted with chloroform $(400 \mu \mathrm{l})$, precipitated with isopropanol (400 $\mu \mathrm{l})$, washed with ethanol $(1 \mathrm{ml})$, and resuspended in 40 $\mu \mathrm{l}$ of distilled water. RNA concentrations and purity were determined by absorbance at 260 and $280 \mathrm{~nm}$. Samples exhibiting an absorbance ratio (260/280) greater than or equal to 1.8 were used.

For the cell sample, the protocol used for RNA extraction was a modification of the RNeasy Mini Kit (Qiagen, Valencia, CA, USA) procedure. Briefly, AmCA hydrogels containing cells were diced in a mixture of $1.5 \mathrm{ml}$ QG buffer (Qiagen) and $2 \mathrm{ml}$ RLT buffer (74104, Qiagen). Samples were kept at room temperature until complete dissolution and then stored at $-20{ }^{\circ} \mathrm{C}$. After defrosting, samples were homogenized and supplemented with $2 \mathrm{ml}$ $70 \%$ ethanol. Subsequent RNA purification steps were performed as described by the manufacturer, and RNA quantity and quality were assessed using a Nanodrop 2000 (ThermoFisher Scientific, Waltham, MA, USA).

First-strand cDNA was obtained by reverse transcription using $2 \mu \mathrm{g}$ of total RNA. The reaction was conducted in $25 \mu \mathrm{l}$ buffer containing $0.5 \mu \mathrm{g}$ oligo(dT) 12-18 primer (Promega, Madison, WI, USA), $50 \mathrm{mM}$ Tris- $\mathrm{HCl}$ (pH 8.3), $75 \mathrm{mM} \mathrm{KCl}, 3 \mathrm{mM} \mathrm{MgCl}, 40 \mathrm{mM}$ dithiothreitol, $0.5 \mathrm{mM}$ deoxynucleotide triphosphate mixture (Promega), 10 U RNase inhibitor (Promega), and $200 \mathrm{U}$ Moloney murine leukemia virus (MMLV) reverse transcriptase (Promega). After incubation at $37^{\circ} \mathrm{C}$ for $60 \mathrm{~min}$, the reaction was stopped by heating at $70^{\circ} \mathrm{C}$ for $5 \mathrm{~min}$. The obtained cDNA was used as a template for PCR amplification using the gene-specific primers. Primer sequences are shown in Table 1. PCR amplification of CDNA was performed in an automated thermal cycler (PC 320, Astec, Osaka, Japan) in a final volume of $25 \mu \mathrm{l}$ containing $4 \mu \mathrm{l}$ cDNA solution, $20 \mathrm{mM}$ Tris- $\mathrm{HCl}$ (pH 8.4), $50 \mathrm{mM} \mathrm{KCl}, 1.5 \mathrm{mM} \mathrm{MgCl}_{2}, 0.1 \%$ Triton X-100, $0.2 \mathrm{mM}$ deoxynucleotide triphosphate mixture (Promega), 0.5 pmol of each primer, and $5 \mathrm{U}$ Taq DNA polymerase (M3001, Promega). Amplified products were analyzed by electrophoresis in $2 \%$ agarose gel and visualized by ethidium bromide staining under UV light. Band intensities of PCR products were measured using an image analysis program (MetaMorph, Universal Imaging Corporation, Downingtown, PA, USA). Results were expressed as ratios versus GAPDH mRNA amplified from the same cDNA samples.

\section{Western blot analysis}

To determine protein expression levels, EL4 cells cultured in 2D with or without treatment with Tiam1/Rac1 inhibitor (NSC23766) were pelleted by centrifugation at $2,000 \mathrm{rpm}$ at $4^{\circ} \mathrm{C}$ for $5 \mathrm{~min}$. After washing the hydrogels with ice cold PBS, EL4 cells cultured in 3D AmCA hydrogel for 7 and 10 days with or without treatment with Tiam1/Rac1 inhibitor (NSC23766) were harvested and washed twice with ice cold PBS. Then, the cells were incubated in ice-cold RIPA lysis buffer containing a cocktail of protease inhibitors $(0.1 \mathrm{mM}$ phenyl methane sulfonyl fluoride, $5 \mathrm{mg} / \mathrm{ml}$ aprotinin, 5 $\mathrm{mg} / \mathrm{ml}$ pepstatin A, and $1 \mathrm{mg} / \mathrm{ml}$ chymostatin (9806S, Cell Signaling Technology, Denver, MA, USA) for 30 min for 2D-cultured cells and $3 \mathrm{~h}$ for 3D-cultured cells on ice. During incubation in lysis buffer, cell lysates were vortexed at each $10 \mathrm{~min}$ interval and then centrifuged at $13,000 \mathrm{rpm}$ for $30 \mathrm{~min}$ at $4^{\circ} \mathrm{C}$. After centrifugation, supernatants were collected as whole cell extracts. Protein concentration was determined using the bicinchoninic acid (BCA) protein assay (B9643, Sigma-Aldrich). Equal protein concentrations from each sample were mixed with Laemmli sample buffer, loaded, and then electrophoresed by sodium dodecyl sulfate-polyacrylamide gel electrophoresis (SDS-PAGE) on $8-12 \%(\mathrm{v} / \mathrm{v})$ resolving gel and blotted onto a polyvinylidene fluoride membrane (Millipore, Bedford, MA, USA) via semi-dry transfer (IPVH00010, Bio-Rad, Hercules, CA, USA). The membrane was incubated in blocking buffer (5\% BSA) and probed with mouse anti-MMP-2 (sc-13594), antiMMP-9 (sc-12759), anti-Bcl-2 (sc-7382), anti-Bcl-xL (sc7195), and anti-Bax (sc-20067) antibodies as well as rabbit anti-VEGF (sc-152) and anti-Tiam1 (sc-872) antibodies (all from Santa Cruz Biotechnology, Santa Cruz, CA, 
USA). The blots were then incubated with peroxidaseconjugated goat anti-mouse and anti-rabbit secondary antibodies (7076 and 7074, respectively, Cell Signaling Technology). Bound antibody was detected using enhanced chemiluminescence (ECL, Super Signal West Pico Chemiluminescent Substrate kit, Pierce, Rockford, IL, USA) following the manufacturer's instructions. Images were captured and quantified with a LAS-3000 imaging system (Fujifilm, Tokyo, Japan). Intensities of the bands were digitized using MultiGauge software (Fujifilm, Science Lab 2005, Japan).

\section{Sensitivity test to antitumor agents}

After EL4 cells were cultured in 2D and in 3D for 10 days, cells were treated in serum-free media with doxorubicin $(1 \mu \mathrm{M})$ alone or in combination with pretreatment of Tiam1/Rac1 inhibitor $(100 \mu \mathrm{M}$ NSC23766), Notch inhibitor (5 $\mathrm{MM}$ DAPT), or both for $24 \mathrm{~h}$. To determine cell viability, the colorimetric WST1 conversion assay (EZ-Cytox Assay Kit, Daeil Lab Service) was used. In brief, WST-1 reagent $(20 \mu \mathrm{l})$ was added to each well, after which cells were incubated for $2 \mathrm{~h}$ in a humidified incubator at $37^{\circ} \mathrm{C}$ under $5 \% \mathrm{CO}_{2}$. The absorbance of the formazan dye, generated by the reaction between dehydrogenase and WST-1 in metabolically active cells, was measured using a microplate reader (Tecan, Männedorf, Switzerland) at $450 \mathrm{~nm}$ according to the manufacturer's instructions. Percent cell viability was calculated. The morphology and size of cell spheroids were assessed at desired time points under a phase contrast microscope. All experiments were performed at least thrice.

\section{Confocal laser scanning microscopy}

For confocal laser scanning microscopic analysis, EL4 cells $\left(1 \times 10^{5}\right.$ cells $\left./ \mathrm{ml}\right)$ were encapsulated in AmCA hydrogels, and cultured at $37^{\circ} \mathrm{C}$ in a $5 \% \mathrm{CO}_{2}$ humidified incubator for 10 days. Cultured cells in $2 \mathrm{D}$ and hydrogels, and $5 \mu \mathrm{m}$-thick, frozen sections of in vivo tumor were washed with $\mathrm{PBS}$ and then fixed with cold $4 \%$ paraformaldehyde in $0.1 \mathrm{M}$ phosphate buffer for $20 \mathrm{~min}$. The fixative was then removed by washing the hydrogels three times for 5 min with cold PBS followed by permeabilization with $0.1 \%$ Triton X-100 in PBS for 5 min. After washing with cold PBS, they were incubated with 2\% BSA (Sigma-Aldrich) for $1 \mathrm{~h}$ at room temperature. Excess solution was then removed and samples were incubated overnight at $4^{\circ} \mathrm{C}$ with $\mathrm{PE}$ labeled anti-CD117 (c-Kit) and FITC-labeled anti-Sca-1 monoclonal antibodies (mAbs, 553355 and 557405, respectively, BD Biosciences, San Jose, CA, USA), or anti-Tiam1 antibody (sc-872, Santa Cruz Biotechnology), rinsed in cold PBS, and mounted on glass slides using Vectashield $^{\circledR}$ containing DAPI (Vector Laboratories). Cell fluorescence was observed using a confocal laser scanning microscope (FV1000 IX81, Olympus, Tokyo, Japan).

\section{Flow cytometry}

Exposure of phosphatidylserine on the cell surface in apoptotic cells was detected with Annexin V-FITC Apoptosis Detection Kit (556570, BD Biosciences) according to the manufacturer's instructions. In brief, cells were incubated with doxorubicin at a concentration of $1 \mu \mathrm{M}$ for $24 \mathrm{~h}$. Apoptotic response assessment was detected by staining with fluorescein isothiocyanate (FITC)-labeled annexin V using FACSCanto II flow cytometer (BD Biosciences). At least $1 \times 10^{5}$ cells were used for each assessment. To obtain cell suspension prior to flow cytometry analysis, the hydrogel debris was removed from cells by filtering the cell-polymer suspension through a 70- $\mu \mathrm{m}$ cell strainer (93070, SPL Life Sciences, Gyeonggi-do, Korea) to eliminate the hydrogel debris and all remaining cell clumps. Collected cells were washed twice with ice-cold PBS containing 1\% FBS and $0.1 \%$ sodium azide, and incubated with FITC-conjugated Annexin $\mathrm{V}$ and propidium iodide (PI) for $20 \mathrm{~min}$ at room temperature in the dark. After staining, an electronic gate was set on the lymphoma cells using forward and side scatter characteristics.

To detect lymphoma stem cell population, EL4 cells were harvested from the 3D AmCA hydrogel cultured for 10 days by pipetting, washed with the culture medium containing $1 \%$ BSA and $0.1 \%$ sodium azide, and filtered through a $70-\mu \mathrm{m}$ cell strainer (SPL Life Sciences). Phenotypic analysis of cell surface marker expression was performed by flow cytometry. Briefly, cells were washed twice with HBSS, and resuspended in the cell-staining buffer. Cells were immunostained for cell surface markers by incubating them for $30 \mathrm{~min}$ with PE-Cy7-labeled anti-c-Kit (565595, BD Biosciences), and APC-labeled anti-Sca-1 mAbs (108111, BioLegend, San Diego, CA, USA). Cells were washed twice and then resuspended in $50 \mu \mathrm{l}$ of cell-staining buffer. For control, 2D-cultured cells were used. FACS analysis was performed using a FACS Canto-II flow cytometer (BD Biosciences). In all the experiments, the forward scatter and the side scatter were adjusted for each sample using appropriate unstained cells to eliminate dead cells and debris. Autofluorescence signals were eliminated by adjusting the signal outputs from designated channels, and the sensitivity was adjusted to collect a gated population of cells. Flow cytometry data were analyzed using FlowJo 10.3.0 (Tree Star, Ashland, OR, USA).

\section{Fluorescence-activated cell sorting}

To disperse cells in a single cell suspension from the hydrogel matrix, the 10-day-AmCA hydrogels with embedded cells was thoroughly mixed with RPMI-1640 
Table 1: RT-PCR primer names and their sequences

\begin{tabular}{lll}
\hline Gene name & Forward (5'-3') & Reverse (5'-3') \\
\hline Notch-1 & CCCAGCAGGTGCAGCCACAG & GGTGATCTGGGACGGCATGG \\
Notch-2 & ATGTGGACGAGTGTCTGTTGC & GGAAGCATAGGCACAGTCATC \\
Notch-3 & ACACTGGGAGTTCTCTGT & GTCTGCTGGCATGGGATA \\
Notch-4 & AAGCGACACGTACGAGTCTGG & ATAGTTGCCAGCTACTTGTGG \\
Hes-1 & CCAGCCAGTGTCAACACGA & AATGCCGGGAGCTATCTTTCT \\
Hey-1 & TCTCCCTTCACCTCACTGCT & CACGCCACTATGCTCAATGT \\
MDR1 & CATTGGTGTGGTGAGTCAGG & CTCTCTCACCAACCAGGGTG \\
MRP1 & GTTCCCTCCGCATGAACTTG & CTGGCTCATGCCTGGACTCTG \\
BCRP & TCTCCTTGCCAGATAAGAGGGG & TGCCTCAAGAGACAGGCAAA \\
HIF-1 $\alpha$ & AGCCCTAGATGGCTTTGTGA & TATCGAGGCTGTGTCGACTG \\
Tiam1 & AACTTCACAAGTTACACCCACTC & CAGAAACCCCAGGCCAAACA \\
Rac1 & AACCTGCCTGCTCATCAGTT & TGACAGCACCGATCTCTTT \\
c-Myc & AAGGGAAGACGATGACGG & TGAGAAACCGCTCCACATA \\
GAPDH & TGGAGAAACCTG CCAAGTATG & TTGTCATACCAGGAAATGAGC \\
\hline
\end{tabular}

medium using a pipette. The cell-polymer suspension was washed with the culture medium and filtered through a $70-\mu \mathrm{m}$ cell strainer (SPL Life Sciences) to eliminate the hydrogel debris and all remaining cell clumps. After washing cells with PBS at least twice, the cells were resuspended at a concentration of 4-5 million $/ \mathrm{ml}$. The cells were incubated with PE-CY7-labeled anti-c-Kit (558163, BD Biosciences) and APC-labeled anti-Sca-1 (557405, BD Biosciences) $\mathrm{mAbs}$ while agitating in an orbital shaker at $200 \mathrm{rpm}$ for $45 \mathrm{~min}$ at $4^{\circ} \mathrm{C}$ in staining buffer containing PBS with $1 \%$ BSA and $0.1 \%$ sodium azide, washed twice in a wash buffer, and resuspended in a sort buffer containing PBS with $1 \%$ BSA. Then, the cells were sorted through a $100 \mu \mathrm{m}$ nozzle at a sheath pressure of $20 \mathrm{psi}$ and a drop drive frequency of $30 \mathrm{kHz}$ into c- $\mathrm{Kit}^{+} /$ Sca- $1^{+}$and $\mathrm{c}-\mathrm{Kit} / \mathrm{Sca}-1^{-}$cell populations on the FACSAria III cell sorter (BD Biosciences) using FACSDiva software. A highly pure sorting modality (4-way purity sorting for FACSAria III) was chosen. The flow rate during the sorting was approximately 8000 events $/ \mathrm{sec}$. The appropriate forward scatter and side scatter gating were used to isolate viable cells. Gates were set with reference to negative controls. The sorting speed was adjusted to ensure sorting efficiency above $90 \%$. Sorted cells were collected in $5 \mathrm{ml}$ polypropylene tubes containing $1 \mathrm{ml}$ collection medium (RPMI 1640 media supplemented with $20 \%$ FBS).

\section{Abbreviations}

AIDS, acquired immune deficiency syndrome; 2D, 2-dimensional; 3D, 3-dimensional; 5-FU, 5-fluorouracil; ABCB1, ATP-binding cassette subfamily $B$ member 1; AmCA, alginate/marine collagen/agarose; ATCC, American Type Culture Collection; BCRP, breast cancer resistance protein; BSA, bovine serum albumin; CLL, chronic lymphocytic leukemia; DAPI, 4,6-diamidino2-phenylindole; DAPT, N-[N-(3,5-difluorophenacetyl)L-alanyl]-S-phenylglycine t-butyl ester; ECL, enhanced chemiluminescence; ECM, extracellular matrix; EMT, epithelial-mesenchymal transition; FITC, fluorescein isothiocyanate; GDP, guanosine diphosphate; GTP, guanosine triphosphate; HIF-1 $\alpha$, hypoxia -inducible factor-1 $\alpha$; MC, marine collagen; MDR1, multidrug resistance protein 1; MMLV, murine leukemia virus; MMP, matrix metalloproteinases; P-gp, permeability glycoprotein; PP2A, protein phosphatase 2A; SDSPAGE, sodium dodecyl sulfate-polyacrylamide gel electrophoresis; Tiam1, T-cell lymphoma invasion and metastasis 1; VEGF, vascular endothelial growth factor.

\section{Author contributions}

Yoon $\mathrm{S}$ conceived and supervised the study, designed the experiments, analyzed the data, and wrote 
the manuscript. Ikram $\mathrm{M}$ and Lim $\mathrm{Y}$ performed the experiments, analyzed the data and wrote the manuscript. Baek SY, Jin SW, Jeong YH and Kwak JY analyzed the data. All authors have read the paper and approved it to be published.

\section{CONFLICTS OF INTEREST}

The authors declare no conflicts of interest.

\section{FUNDING}

This work was supported by the Pioneer Research Center Program of the Korean National Research Foundation funded by the Ministry of Science, ICT \& Future Planning (Grant no. 2012-0009667).

\section{REFERENCES}

1. Huh J. Epidemiologic overview of malignant lymphoma. Korean J Hematol. 2012; 47:92-104.

2. Leuchte K, Schlaak M, Stadler R, Theurich S, von Bergwelt-Baildon M. Innovative Treatment Concepts for Cutaneous T-Cell Lymphoma Based on Microenvironment Modulation. Oncol Res Treat. 2017; 40:262-269.

3. Godugu C, Patel AR, Desai U, Andey T, Sams A, Singh M. AlgiMatrix ${ }^{\mathrm{TM}}$ based $3 \mathrm{D}$ cell culture system as an invitro tumor model for anticancer studies. PLoS One. 2013; 8:e53708.

4. Edmondson R, Broglie JJ, Adcock AF, Yang L. Threedimensional cell culture systems and their applications in drug discovery and cell-based biosensors. Assay Drug Dev Technol. 2014; 12:207-218.

5. Fang Y, Eglen RM. Three-Dimensional Cell Cultures in Drug Discovery and Development. SLAS DISCOVERY: Advancing Life Sciences R\&D. 2017; 22:456-472.

6. Shin S, Ikram M, Subhan F, Kang HY, Lim Y, Lee R, Jin $\mathrm{S}$, Jeong YH, Kwak JY, Na YJ. Alginate-marine collagenagarose composite hydrogels as matrices for biomimetic 3D cell spheroid formation. RSC Adv. 2016; 6:46952-46965.

7. Kumar A, Gautam B, Dubey C, Tripathi PK. A review: role of doxorubicin in treatment of cancer. Int J Pharm Sci Res. 2014; 5:4105

8. Shiraga K, Sakaguchi K, Senoh T, Ohta T, Ogawa S, Sawayama T, Mouri H, Fujiwara A, Tsuji T. Modulation of doxorubicin sensitivity by cyclosporine A in hepatocellular carcinoma cells and their doxorubicin-resistant sublines. J Gastroenterol Hepatol. 2001; 16:460-466.

9. Huesker M, Folmer Y, Schneider M, Fulda C, Blum HE, Hafkemeyer P. Reversal of drug resistance of hepatocellular carcinoma cells by adenoviral delivery of anti-MDR1 ribozymes. Hepatology. 2002; 36:874-884.

10. Cox J, Weinman S. Mechanisms of doxorubicin resistance in hepatocellular carcinoma. Hepat Oncol. 2016; 3:57-59.
11. Artavanis-Tsakonas S, Rand MD, Lake RJ. Notch signaling: cell fate control and signal integration in development. Science. 1999; 284:770-776.

12. Jundt F, Anagnostopoulos I, Förster R, Mathas S, Stein H, Dörken B. Activated Notch1 signaling promotes tumor cell proliferation and survival in Hodgkin and anaplastic large cell lymphoma. Blood. 2002; 99:3398-3403.

13. Guo H, Lu Y, Wang J, Liu X, Keller ET, Liu Q, Zhou Q, Zhang J. Targeting the Notch signaling pathway in cancer therapeutics. Thorac Cancer. 2014; 5:473-486.

14. Herranz D, Ambesi-Impiombato A, Palomero T, Schnell SA, Belver L, Wendorff AA, Xu L, Castillo-Martin M, Llobet-Navás D, Cordon-Cardo C, Clappier E, Soulier J, Ferrando AA. A NOTCH1-driven MYC enhancer promotes $\mathrm{T}$ cell development, transformation and acute lymphoblastic leukemia. Nat Med. 2014; 20:1130-1137.

15. Wang Z, Li Y, Ahmad A, Azmi AS, Banerjee S, Kong D, Sarkar FH. Targeting Notch signaling pathway to overcome drug resistance for cancer therapy. Biochimica et Biophysica Acta. 2010; 1806:258-267.

16. Wang J, Wakeman TP, Lathia JD, Hjelmeland AB, Wang XF, White RR, Rich JN, Sullenger BA. Notch promotes radioresistance of glioma stem cells. Stem cells. 2010; 28:17-28.

17. Habets GG, Scholtes EH, Zuydgeest D, van der Kammen RA, Stam JC, Berns A, Collard JG. Identification of an invasion-inducing gene, Tiam-1, that encodes a protein with homology to GDP-GTP exchangers for Rho-like proteins. Cell. 1994; 77:537-549.

18. Saxena M, Dykes SS, Malyarchuk S, Wang AE, Cardelli JA, Pruitt K. The sirtuins promote Dishevelled-1 scaffolding of TIAM1, Rac activation and cell migration. Oncogene. 2015; 34:188-198.

19. $\mathrm{Xu} \mathrm{K}$, Tian $\mathrm{X}$, Oh SY, Movassaghi M, Naber SP, Kuperwasser C, Buchsbaum RJ. The fibroblast Tiam1osteopontin pathway modulates breast cancer invasion and metastasis. Breast Cancer Res. 2016; 18:14.

20. Malliri A, van der Kammen RA, Clark K, van der Valk M, Michiels F, Collard JG. Mice deficient in the Rac activator Tiam1 are resistant to Ras-induced skin tumours. Nature. 2002; 417:867-871.

21. Cordo-Russo RI, Alaniz LD, Saccodossi N, Lompardía S, Blanco G, Alvarez E, García MG, Hajos SE. Hyaluronan induces migration of multidrug-resistant lymphoma cell lines in vitro through Tiam 1 activation by a PI3K-dependent mechanism. Leuk Res. 2010; 34:1525-1532.

22. Hofbauer SW, Krenn PW, Ganghammer S, Asslaber D, Pichler U, Oberascher K, Henschler R, Wallner M, Kerschbaum H, Greil R. Tiam1/Rac1 signals contribute to the proliferation and chemoresistance, but not motility, of chronic lymphocytic leukemia cells. Blood. 2014; 123:2181-2188.

23. Shetzer Y, Solomon H, Koifman G, Molchadsky A, Horesh $\mathrm{S}$, Rotter $\mathrm{V}$. The paradigm of mutant $\mathrm{p} 53$-expressing cancer 
stem cells and drug resistance. Carcinogenesis. 2014; 3:1196-1208.

24. Kim JB. Three-dimensional tissue culture models in cancer biology. Semin Cancer Biol. 2005; 15:365-377.

25. Decaup E, Jean C, Laurent C, Gravelle P, Fruchon S, Capilla F, Marrot A, Al Saati T, Frenois FX, Laurent G, Klein C, Varoqueaux N, Savina A, et al. Anti-tumor activity of obinutuzumab and rituximab in a follicular lymphoma 3D model. Blood Cancer J. 2013; 3:e131.

26. Shah SB, Singh A. Creating artificial lymphoid tissues to study immunity and hematological malignancies. Curr Opin Hematol. 2017; 24:377-383.

27. Birgersdotter A, Baumforth KR, Porwit A, Sundblad A, Falk KI, Wei W, Sjöberg J, Murray PG, Björkholm M, Ernberg I. Three-dimensional culturing of the Hodgkin lymphoma cell-line L1236 induces a HL tissue-like gene expression pattern. Leuk Lymphoma. 2007; 48:2042-2053.

28. Caicedo-Carvajal CE, Liu Q, Remache Y, Goy A, Suh KS. Cancer Tissue Engineering: A Novel 3D Polystyrene Scaffold for In Vitro Isolation and Amplification of Lymphoma Cancer Cells from Heterogeneous Cell Mixtures. J Tissue Eng. 2011; 2011:362326.

29. Gravelle P, Jean C, Familiades J, Decaup E, Blanc A, Bezombes-Cagnac C, Laurent C, Savina A, Fournié JJ, Laurent G. Cell growth in aggregates determines gene expression, proliferation, survival, chemoresistance, and sensitivity to immune effectors in follicular lymphoma. Am J Pathol. 2014; 184:282-295.

30. Tian YF, Ahn H, Schneider RS, Yang SN, Roman-Gonzalez L, Melnick AM, Cerchietti L, Singh A. Integrin-specific hydrogels as adaptable tumor organoids for malignant B and T cells. Biomaterials. 2015; 73:110-119.

31. Habets GG, van der Kammen RA, Stam JC, Michiels F, Collard JG. Sequence of the human invasion-inducing TIAM1 gene, its conservation in evolution and its expression in tumor cell lines of different tissue origin. Oncogene. 1995; 10:1371-1376.

32. Michiels F, Habets GG, Stam JC, van der Kammen RA, Collard JG. A role for Rac in Tiam1-induced membrane ruffling and invasion. Nature. 1995; 375:338-340.

33. Zhou H, Kann MG, Mallory EK, Yang YH, Bugshan A, Binmadi NO, Basile JR. Recruitment of Tiam1 to Semaphorin 4D Activates Rac and Enhances Proliferation, Invasion, and Metastasis in Oral Squamous Cell Carcinoma. Neoplasia. 2017; 19:65-74.

34. Li Z, Liu Q, Piao J, Hua F, Wang J, Jin G, Lin Z, Zhang Y. Clinicopathological implications of Tiam1 overexpression in invasive ductal carcinoma of the breast. BMC Cancer. 2016; 16:681.

35. De P, Carlson JH, Jepperson T, Willis S, Leyland-Jones B, Dey N. RAC1 GTP-ase signals Wnt-beta-catenin pathway mediated integrin-directed metastasis-associated tumor cell phenotypes in triple negative breast cancers. Oncotarget. 2017; 8:3072-3103. https://doi.org/10.18632/oncotarget.13618.
36. Huang J, Ye X, Guan J, Chen B, Li Q, Zheng X, Liu L, Wang S, Ding Y, Ding Y, Chen L. Tiam1 is associated with hepatocellular carcinoma metastasis. Int J Cancer. 2013; 132:90-100. https://doi.org/10.1002/ijc.27627. Erratum in: Int J Cancer. 2015; 137:E14. Int J Cancer. 2015; 137:E16.

37. Wartenberg M, Frey C, Diedershagen H, Ritgen J, Hescheler J, Sauer H. Development of an intrinsic P-glycoproteinmediated doxorubicin resistance in quiescent cell layers of large, multicellular prostate tumor spheroids. Int J Cancer. 1998; 75:855-863.

38. Sánchez C, Mendoza P, Contreras HR, Vergara J, McCubrey JA, Huidobro C, Castellón EA. Expression of multidrug resistance proteins in prostate cancer is related with cell sensitivity to chemotherapeutic drugs. Prostate. 2009; 69:1448-1459.

39. Zhu W, Xu H, Zhu D, Zhi H, Wang T, Wang J, Jiang B, Shu Y, Liu P. miR-200bc/429 cluster modulates multidrug resistance of human cancer cell lines by targeting BCL2 and XIAP. Cancer Chemother Pharmacol. 2012; 69:723-731.

40. Wei LY, Roepe PD. Low external pH and osmotic shock increase the expression of human MDR protein. Biochemistry. 1994; 33:7229-7238.

41. Milane L, Ganesh S, Shah S, Duan ZF, Amiji M. Multimodal strategies for overcoming tumor drug resistance: hypoxia, the Warburg effect, stem cells, and multifunctional nanotechnology. J Control Release. 2011; 155:237-247.

42. Vinci M, Gowan S, Boxall F, Patterson L, Zimmermann M, Court W, Lomas C, Mendiola M, Hardisson D, Eccles SA. Advances in establishment and analysis of three-dimensional tumor spheroid-based functional assays for target validation and drug evaluation. BMC Biol. 2012; 10:29.

43. Zanoni M, Piccinini F, Arienti C, Zamagni A, Santi S, Polico R, Bevilacqua A, Tesei A. 3D tumor spheroid models for in vitro therapeutic screening: a systematic approach to enhance the biological relevance of data obtained. Sci Rep. 2016; 6:19103.

44. Hutchinson L, Kirk R. High drug attrition rates--where are we going wrong? Nat Rev Clin Oncol. 2011; 8:189-190.

45. dit Faute MA, Laurent L, Ploton D, Poupon MF, Jardillier JC, Bobichon H. Distinctive alterations of invasiveness, drug resistance and cell-cell organization in 3D-cultures of MCF-7, a human breast cancer cell line, and its multidrug resistant variant. Clin Exp Metastasis. 2002; 19:161-168.

46. Correia AL, Bissell MJ. The tumor microenvironment is a dominant force in multidrug resistance. Drug Resist Updat. 2012; 15:39-49.

47. Tosello V, Ferrando AA. The NOTCH signaling pathway: role in the pathogenesis of T-cell acute lymphoblastic leukemia and implication for therapy. Ther Adv Hematol. 2013; 4:199-210.

48. Wang Z, Li Y, Ahmad A, Azmi AS, Banerjee S, Kong D, Sarkar FH. Targeting Notch signaling pathway to overcome drug resistance for cancer therapy. Biochim Biophys Acta. 2010; 1806:258-267. 
49. Cho S, Lu M, He X, Ee PL, Bhat U, Schneider E, Miele L, Beck WT. Notch1 regulates the expression of the multidrug resistance gene ABCC1/MRP1 in cultured cancer cells. Proc Natl Acad Sci U S A. 2011; 108:20778-20783.

50. Huang J, Chen Y, Li J, Zhang K, Chen J, Chen D, Feng B, Song H, Feng J, Wang R, Chen L. Notch-1 Confers Chemoresistance in Lung Adenocarcinoma to Taxanes through AP-1/microRNA-451 Mediated Regulation of MDR-1. Mol Ther Nucleic Acids. 2016; 5:e375.

51. Clarke MF, Dick JE, Dirks PB, Eaves CJ, Jamieson CH, Jones DL, Visvader J, Weissman IL, Wahl GM. Cancer stem cells--perspectives on current status and future directions: AACR Workshop on cancer stem cells. Cancer Res. 2006; $66: 9339-9344$.

52. Zabierowski SE, Herlyn M. Learning the ABCs of melanoma-initiating cells. Cancer Cell. 2008; 13:185-187.
53. Phillips TM, McBride WH, Pajonk F. The response of $\mathrm{CD} 24^{-/ \text {low }} / \mathrm{CD} 44^{+}$breast cancer-initiating cells to radiation. J Natl Cancer Inst. 2006; 98:1777-1785.

54. Ricci-Vitiani L, Lombardi DG, Pilozzi E, Biffoni M, Todaro M, Peschle C, De Maria R. Identification and expansion of human colon-cancer-initiating cells. Nature. 2007; 445:111115.

55. Engler AJ, Sen S, Sweeney HL, Discher DE. Matrix elasticity directs stem cell lineage specification. Cell. 2006; 126:677-689.

56. Yamada KM, Cukierman E. Modeling tissue morphogenesis and cancer in 3D. Cell. 2007; 130:601-610. 